\title{
Synthetic Pathway Determines the Nonequilibrium Crystallography of Li- and Mn-Rich Layered Oxide Cathode Materials
}

Ashok S. Menon, Seda Ulusoy, Dickson O. Ojwang, Lars Riekehr, Christophe Didier, Vanessa K. Peterson, Germán Salazar-Alvarez, Peter Svedlindh, Kristina Edström, Cesar Pay Gomez, and William R. Brant*

Cite This: ACS Appl. Energy Mater. 2021, 4, 1924-1935

Read Online

ACCESS | 네 Metrics \& More | 回 Article Recommendations | st Supporting Information

ABSTRACT: Li- and Mn-rich layered oxides show significant promise as electrode materials for future Li-ion batteries. However, an accurate description of its crystallography remains elusive, with both single-phase solid solution and multiphase structures being proposed for high performing materials such as $\mathrm{Li}_{1.2} \mathrm{Mn}_{0.54} \mathrm{Ni}_{0.13} \mathrm{Co}_{0.13} \mathrm{O}_{2}$. Herein, we report the synthesis of singleand multiphase variants of this material through sol-gel and solidstate methods, respectively, and demonstrate that its crystallography is a direct consequence of the synthetic route and not necessarily an inherent property of the composition, as previously argued. This was accomplished via complementary techniques that probe the bulk and local structure followed by in situ methods to map the synthetic progression. As the electrochemical performance

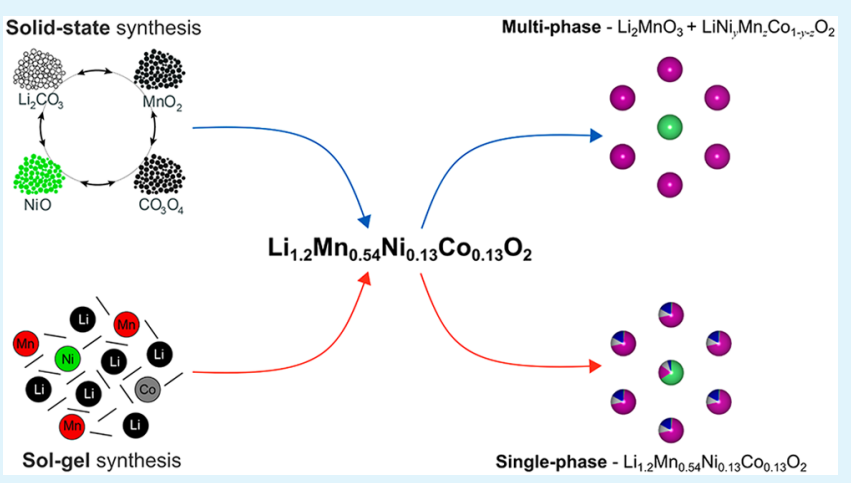
and anionic redox behavior are often rationalized on the basis of the presumed crystal structure, clarifying the structural ambiguities is an important step toward harnessing its potential as an electrode material.

KEYWORDS: $\mathrm{Li}$ - and Mn-rich layered oxides, Li-ion battery cathodes, synthesis-structure relationships, anionic redox materials, stacking faulted materials

\section{INTRODUCTION}

The search for novel high energy density positive electrode materials for Li-ion batteries has led to the discovery of several promising but increasingly complex materials, such as the Liand $\mathrm{Mn}$-rich layered transition metal oxide system. ${ }^{1}$ In particular, $\mathrm{Li}_{1.2} \mathrm{Mn}_{0.54} \mathrm{Ni}_{0.13} \mathrm{Co}_{0.13} \mathrm{O}_{2}$ (LMNCO), is considered a likely candidate for commercialization due to its high specific capacity $(\sim 300 \mathrm{mAh} / \mathrm{g})$, facilitated by the joint participation of cations and anions in its functional redox process. ${ }^{2}$ However, harnessing the high capacity comes at the cost of irreversible capacity loss and voltage hysteresis over continued electrochemical cycling originating from structural transformations in the material. ${ }^{2,3}$ Among other approaches, crystallographic modifications have been successful in improving the electrochemical performance of LMNCO, although much work remains to be done. ${ }^{4-6}$

Efforts aimed at further developing the LMNCO system must be complemented by fundamental investigations of physical characteristics and properties. This is especially relevant because of the chemical and structural complexity of LMNCO, where gaps in our knowledge of the crystallographic structure exist. LMNCO is argued to exist in multiple crystallographic forms (Figure 1a): as a single-phase (SP) solid solution, expressed as $\mathrm{Li}\left[\mathrm{Li}_{0.2} \mathrm{Mn}_{0.54} \mathrm{Ni}_{0.13} \mathrm{Co}_{0.13} \mathrm{O}_{2}\right] \mathrm{O}_{2}$, ,8 and as a multiphase (MP) material, existing as an intergrowth of cation-ordered monoclinic $\mathrm{Li}_{2} \mathrm{MnO}_{3}{ }^{9}$ and transition metal (TM)-disordered hexagonal $\mathrm{LiNi}_{0.33} \mathrm{Mn}_{0.33} \mathrm{Co}_{0.33} \mathrm{O}_{2}{ }^{10}$ phases $\left(x\left[\mathrm{Li}_{2} \mathrm{MnO}_{3}\right] \cdot(1-x)\left[\mathrm{LiTMO}_{2}\right], x=0.5\right) .{ }^{11-13}$ These phases are said to exist as domains integrated through a shared cubic close-packed (ccp) $\mathrm{O}^{2-}$ substructure. Although both models possess long-range $\mathrm{Li}-\mathrm{TM}$ superstructure ordering, the manifestation of this ordering in the TM layers differs. In the single-phase model, superstructure arises from preferential occupation of $2 b$ and $4 g(\mathrm{C} 2 / \mathrm{m})$ crystallographic sites by $\mathrm{Li}$ and $\mathrm{Mn}$, respectively, with $\mathrm{Co}$ and $\mathrm{Ni}$ distributed across the two sites. ${ }^{14}$ In the multiphase model, the superstructure is formed by $\mathrm{Li}$ and $\mathrm{Mn}$ ordering within the $\mathrm{Li}_{2} \mathrm{MnO}_{3}$ phase/ domain, where $\mathrm{Li}$ in the TM layer is surrounded exclusively by Mn. ${ }^{113}$ However, these models are idealized disorder-free

Received: December 4, 2020

Accepted: February 1, 2021

Published: February 10, 2021 
(a) LMNCO models Single-phase
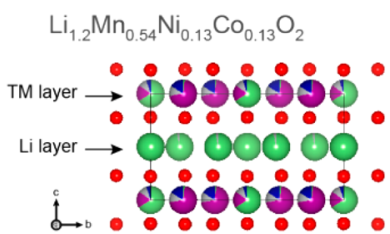

Multi-phase

$\mathrm{Li}_{2} \mathrm{MnO}_{3}$

$+\quad \mathrm{LiNi}_{0.33} \mathrm{Mn}_{0.33} \mathrm{Co}_{0.33} \mathrm{O}_{2}$ $\because 0^{\circ} \circ$ TM layer $\longrightarrow$ ட Li layer $\longrightarrow 00000$ -

$\stackrel{\bullet}{\rightarrow b}$ $\because \because \div \circ$

(c)

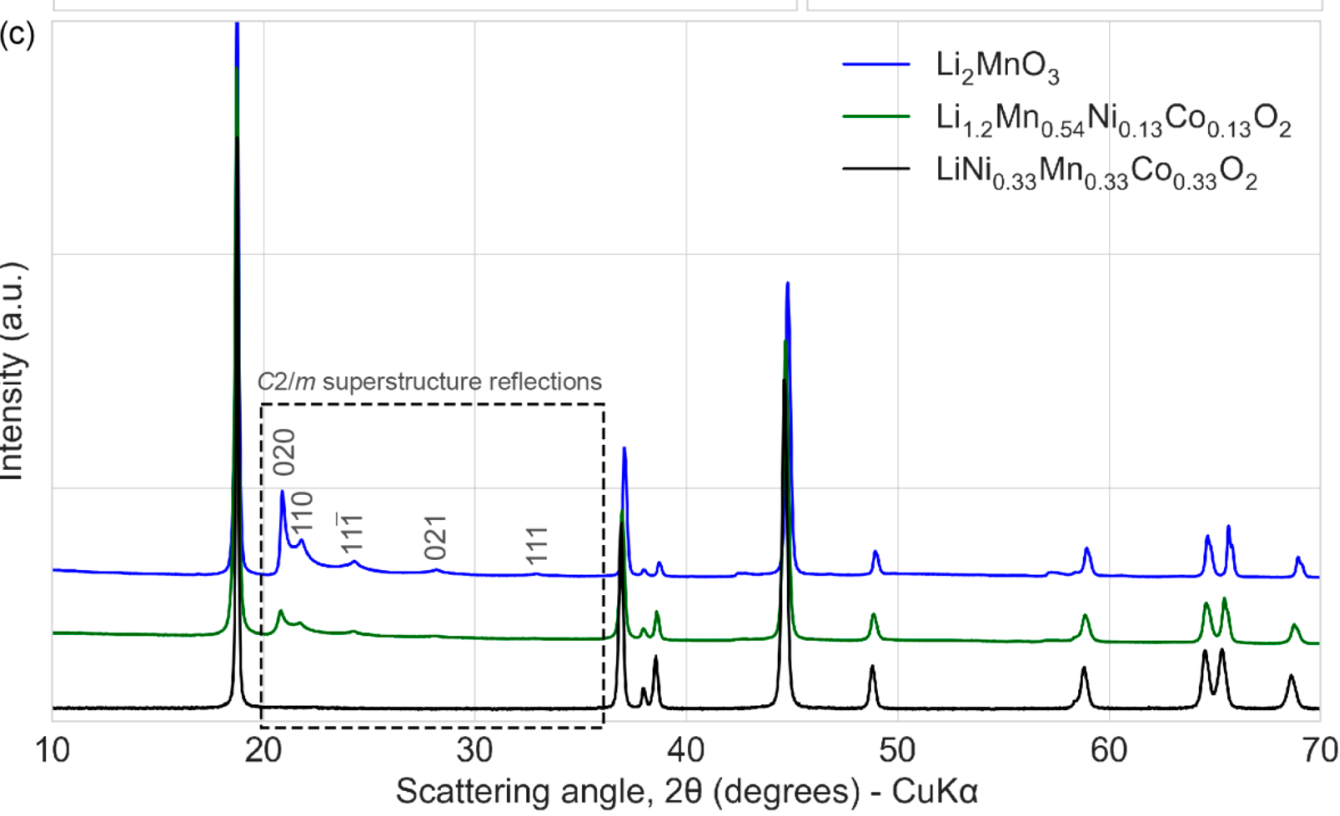

(b) Structural defects

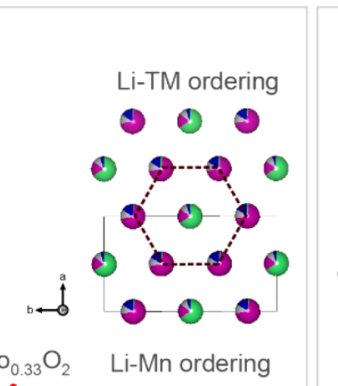

!

Li-Ni mixing

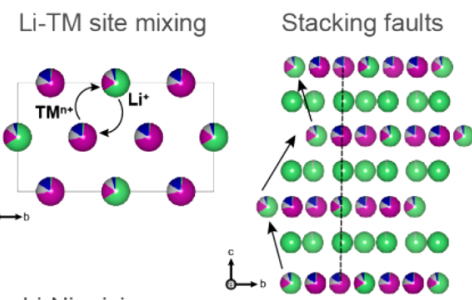

$10 \mathrm{Li}$

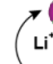

$\mathrm{Li}^{+}$

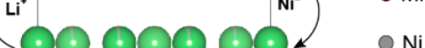

i 0000000 co

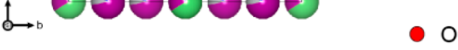

1. (a) Single- and multiphase LMNCO structure models. The Li-transition metal (TM) and Li-Mn ordering in the corresponding models are also shown. Dashed hexagons represent superstructures. (b) Structural defects that can occur in Li- and Mn-rich layered transition metal oxides. (c) Stacked normalized X-ray diffraction patterns of $\mathrm{Li}_{2} \mathrm{MnO}_{3}, \mathrm{Li}_{1.2} \mathrm{Mn}_{0.54} \mathrm{Ni}_{0.13} \mathrm{Co}_{0.13} \mathrm{O}_{2}$, and $\mathrm{LiNi}_{0.33} \mathrm{Mn}_{0.33} \mathrm{Co}_{0.33} \mathrm{O}_{2}$. The superstructure reflections in $\mathrm{Li}_{2} \mathrm{MnO}_{3}$ and $\mathrm{Li}_{1.2} \mathrm{Mn}_{0.54} \mathrm{Ni}_{0.13} \mathrm{Co}_{0.13} \mathrm{O}_{2}$ are indexed with $\mathrm{C} 2 / m$ space group symmetry.

representations, and in reality, structural disorder occurs leading to variation from the ideal case. ${ }^{7,14}$

Structural characterization of LMNCO is complicated by three kinds of disorders that manifest across different crystallographic length scales; (1) Li-TM site mixing (in the TM layer), (2) stacking faults, and (3) interlayer $\mathrm{Li}^{+}-\mathrm{Ni}^{2+}$ mixing. These are schematically illustrated in Figure $1 \mathrm{~b}$ and have been reported in several works, irrespective of the structure model employed. ${ }^{7,8,11,12}$ Figure 1c shows the X-ray diffraction patterns of LR-TMOs, with that of $\mathrm{LiNi}_{0.33} \mathrm{Mn}_{0.33^{-}}$ $\mathrm{Co}_{0.33} \mathrm{O}_{2}$. The underlying similarity between these compounds due to their layered structure is apparent. The primary difference between the patterns are the superstructure reflections in the $20^{\circ}-35^{\circ}(2 \theta) \mathrm{Cu} \mathrm{K} \alpha$ range (1.4-2.4 $\AA^{-1}$ in $Q$-space) in the Li-rich systems. The diffraction pattern of $\mathrm{LiNi}_{0.33} \mathrm{Mn}_{0.33} \mathrm{Co}_{0.33} \mathrm{O}_{2}$, on the other hand, does not possess superstructure reflections due to the random distribution of TM ions in the TM layer. ${ }^{10}$ The asymmetric broadening of the superstructure reflections (Warren fall ${ }^{15}$ ) in the Li-rich materials originates from the disruption of periodicity in the $c$ direction due to TM layer stacking faults. ${ }^{8,16}$ This disruption can manifest in multiple ways in LMNCO. For example, in the MP model, stacking faults may be caused when $\mathrm{Li}_{2} \mathrm{MnO}_{3}$-like ( $\mathrm{Li}-\mathrm{Mn}$ ) stacking is interrupted by a $\mathrm{LiNi}_{0.33} \mathrm{Mn}_{0.33} \mathrm{Co}_{0.33} \mathrm{O}_{2^{-}}$ like TM-only layer, in addition to irregular stacking of similar layer types.

The determination of LMNCO as single- or multi-phase is nontrivial as the synthesis method has a thermodynamic influence on the material structure. Shukla et al. have shown that the bulk structure of LMNCO is composed of monoclinic phases with randomly stacked domains. ${ }^{7}$ However, the existence of separate $\mathrm{Li}_{2} \mathrm{MnO}_{3}$ and $\mathrm{Li}-\mathrm{TM}-\mathrm{O}_{2}$ domains/phases in LMNCO has also been reported by $\mathrm{Yu}$ et al. (using solidstate method), among others. ${ }^{11,13}$ In addition to slight stoichiometric variations, these studies employ different material synthesis protocols. It is also worth noting that although the effects of parameters such as sintering temperature and synthesis route on the properties of LMNCO have 
been investigated, ${ }^{17-19}$ a specific structural model was assumed for the analysis. However, because of the compositional and crystallographic complexity of LMNCO, it is reasonable to assume that synthetic variations can lead to dissimilar nonequilibrium crystallographic structures, resulting in the aforementioned contradictory observations. ${ }^{20}$ Considering that a thermodynamically stable product is not reached (due to limited heat treatment), a single structure model is often insufficient to describe this system.

The present work investigates the hypothesis that the LMNCO synthetic pathway defines the observed crystal structure. Toward this, LMNCO was intentionally synthesized via two approaches with extremely contrasting degrees of precursor mixing, solid-state and sol-gel, with the intent that each would produce significant crystallographic and morphological differences. The products were characterized over different structural length scales by using X-ray and neutron powder diffraction, Raman spectroscopy, electron microscopy, and magnetic measurements, thus providing a complete structural perspective beyond the "single- vs multi-phase" debate surrounding this material. The observed differences were rationalized through investigation of the synthesis process in situ through thermal and powder diffraction analysis, and synthesis-structure relationships are established.

\section{EXPERIMENTAL SECTION}

Synthesis. $\mathrm{Li}_{1.2} \mathrm{Mn}_{0.54} \mathrm{Ni}_{0.13} \mathrm{Co}_{0.13} \mathrm{O}_{2}$ (LMNCO) samples were synthesized by using solid-state and sol-gel methods. For solidstate synthesis, the precursors:lithium carbonate $\left({ }^{7} \mathrm{Li}_{2} \mathrm{CO}_{3}\right.$, SigmaAldrich, $\left.99 \%{ }^{7} \mathrm{Li}\right)$, manganese(IV) dioxide $\left(\mathrm{MnO}_{2}\right.$, Alfa Aesar, $\left.98 \%\right)$, nickel(II) oxide (NiO, Alfa Aesar, 99\%), and cobalt (II, III) oxide $\left(\mathrm{Co}_{3} \mathrm{O}_{4}\right.$ Alfa Aesar, $\left.99.7 \%\right)$, were thoroughly mixed by using a mortar and pestle. ${ }^{7} \mathrm{Li}_{2} \mathrm{CO}_{3}$ was used to reduce neutron absorption by ${ }^{6} \mathrm{Li}$ in natural $\mathrm{Li}$. An $\sim 10$ wt \% excess of $\mathrm{Li}_{2} \mathrm{CO}_{3}$ was used to compensate for the loss of Li during high-temperature annealing.

The sol-gel precursor was prepared through a modified Pechini sol-gel based method. ${ }^{21}$ Stoichiometric amounts of lithium acetate dihydrate $\left(\mathrm{CH}_{3} \mathrm{COOLi} \cdot 2 \mathrm{H}_{2} \mathrm{O}\right.$, Sigma-Aldrich, reagent grade), manganese(II) acetate tetrahydrate $\left(\left(\mathrm{CH}_{3} \mathrm{COO}\right)_{2} \mathrm{Mn} \cdot 4 \mathrm{H}_{2} \mathrm{O}\right.$, SigmaAldrich, $\geq 99 \%)$, nickel(II) acetate tetrahydrate $\left(\left(\mathrm{CH}_{3} \mathrm{COO}\right)_{2} \mathrm{Ni}\right.$. $\left.4 \mathrm{H}_{2} \mathrm{O}\right)$, Sigma-Aldrich, $\geq 99 \%$ ), and cobalt(II) acetate tetrahydrate $\left(\left(\mathrm{CH}_{3} \mathrm{COO}\right)_{2} \mathrm{Co} \cdot 4 \mathrm{H}_{2} \mathrm{O}\right.$, Sigma-Aldrich, $\left.\geq 99 \%\right)$ were dissolved in 300 $\mathrm{mL}$ of deionized water. An excess of the $\mathrm{Li}$ source, $\sim 2.5 \mathrm{wt} \%$, was again used to account for Li loss during annealing. Similarly, a $300 \mathrm{~mL}$ aqueous solution of citric acid (Sigma-Aldrich, $\geq 99.5 \%$ ) and EDTA (ethylenediaminetetraacetic acid, ACS reagent) was also prepared. The cation:citric acid:EDTA molar ratio was approximately 1:1.5:1. The two solutions were thoroughly mixed by magnetic stirring for $1 \mathrm{~h}$, after which the $\mathrm{pH}$ was adjusted to $\sim 7.5$ by using ammonium hydroxide solution $\left(\mathrm{NH}_{4} \mathrm{OH}\right.$, Sigma-Aldrich, $\left.28-30 \%\right)$. The solution was heated at $120{ }^{\circ} \mathrm{C}$ overnight while stirring, which led to the formation of a dry gel that was then crushed into a powder. This powder was then transferred to an alumina crucible and heated in a muffle furnace in air at $500{ }^{\circ} \mathrm{C}\left(5^{\circ} \mathrm{C} / \mathrm{min}\right.$ ramp $)$ for $5 \mathrm{~h}$ and allowed to cool to room temperature in the furnace.

The two precursors (mixture of powder precursors for the solidstate method and the preheated precursor for the sol-gel method) were separately transferred to an alumina crucible and annealed in air at $900{ }^{\circ} \mathrm{C}\left(5^{\circ} \mathrm{C} / \mathrm{min}\right.$ ramp $)$ for $12 \mathrm{~h}$ by using a muffle furnace. After annealing, they were quenched to room temperature by bringing the crucibles in contact with an aluminium plate.

Two additional samples, $\mathrm{Li}_{2} \mathrm{MnO}_{3}$ and $\mathrm{LiNi}_{0.33} \mathrm{Mn}_{0.33} \mathrm{Co}_{0.33} \mathrm{O}_{2}$, were also studied for comparative purposes. $\mathrm{Li}_{2} \mathrm{MnO}_{3}$ was synthesized in a similar way to sol-gel LMNCO, whereas $\mathrm{LiNi}_{0.33} \mathrm{Mn}_{0.33} \mathrm{Co}_{0.33} \mathrm{O}_{2}$ was obtained commercially from Custom Cells Itzehoe $\mathrm{GmbH}$.

Characterization. Elemental analysis was performed by inductively coupled plasma-optical emission spectroscopy (ICP-OES) measurements with a PerkinElmer ICP-OES Avio 200 system. The powders were dissolved in a $\mathrm{HCl}: \mathrm{HNO}_{3}(3: 1 \mathrm{v} / \mathrm{v})$ solution (ICP grade) and diluted to the required concentration by using a solution of $5 \mathrm{vol} \% \mathrm{HNO}_{3}$ in ultrapure Milli-Q water (blank) prior to the analysis. The PerkinElmer Pure Plus Multielement calibration standard was used as the reference for the ICP-OES measurements.

The particle size and morphology were studied by using a Zeiss LEO 1550 scanning electron microscope (SEM). The powdered samples were spread on carbon tape and coated with a thin layer of AuPd alloy to prevent charging. The images were obtained at an accelerating voltage of $5 \mathrm{kV}$ by using the InLens detector. Powder samples for transmission electron microscopy were prepared by crushing the powder in a mortar followed by sonication in anhydrous ethanol and drop casting the dispersion on a holey-carbon copper grid. Scanning transmission electron microscopy and X-ray energydispersive spectroscopy (STEM-EDX) maps were recorded by using a probe corrected FEI Titan Themis 200 microscope operating at 200 $\mathrm{kV}$ equipped with a four-detector Super-X EDS system. The EDS images were acquired and evaluated with the software ESPRIT 1.9 from Bruker. Quantification was performed standard-less with the Cliff-Lorimer method using theoretical $k$-factors provided by the software.

Thermogravimetric and differential thermal analysis (TG-DTA) were performed simultaneously by using a Netzsch STA 409 thermal analyzer. The precursor mixture was placed in an alumina crucible and heated at $5{ }^{\circ} \mathrm{C} / \mathrm{min}$ from 25 to $900{ }^{\circ} \mathrm{C}$ in air $(60 \mathrm{~mL} / \mathrm{min}$ flow rate $)$.

Synchrotron X-ray diffraction (XRD) experiments were performed on the Powder Diffraction beamline ${ }^{22}$ at the Australian Synchrotron. The powder samples were packed in $0.5 \mathrm{~mm}$ (diameter) quartz capillaries and data collected in transmission mode by using the Mythen II detector from $1^{\circ}$ to $81^{\circ}(2 \theta)$ using a wavelength of $0.7736831(8) \AA(\sim 16 \mathrm{keV})$. Two data sets were collected for $40 \mathrm{~s}$ each with the detector set $0.5^{\circ}$ apart to cover gaps between the detector modules; these were then merged by using the in-house software, PDViPeR. The wavelength and instrumental parameters were determined by using data collected for the NIST $660 \mathrm{~b} \mathrm{\textrm {LBB } _ { 6 }}$ standard reference material. Constant wavelength neutron powder diffraction (NPD) data were collected on the high-resolution neutron powder diffractometer, Echidna, ${ }^{23}$ at the Australian Nuclear Science and Technology Organisation (ANSTO). The solid-state and sol-gel samples were measured by using neutron wavelengths of 1.62183(2) and 1.62189(2) $\AA$, respectively. For the measurement, $\sim 2.1 \mathrm{~g}$ of the solid-state sample and $\sim 0.38 \mathrm{~g}$ of the sol-gel sample were packed into 6 and $9 \mathrm{~mm}$ (diameter) vanadium cans, respectively. Data were collected over a $2 \theta$ range of $5^{\circ}-164^{\circ}$ for a duration of $4 \mathrm{~h}$ for the solid-state sample and $10 \mathrm{~h}$ for the sol-gel sample. The wavelength and the instrumental parameters were determined by using the NIST $660 \mathrm{~b} \mathrm{La}^{11} \mathrm{~B}_{6}$ standard reference material.

In situ synchrotron XRD measurements were performed at the I11 High Resolution Powder Diffraction beamline ${ }^{24}$ at the Diamond Light Source with a wavelength of 0.8265203 (3) $\AA$. The precursor mixture was loaded into a $0.5 \mathrm{~mm}$ (diameter) quartz capillary and heated by a Cyberstar hot-air blower. The capillary, under rotation, was initially heated to $400{ }^{\circ} \mathrm{C}$ at $\sim 12{ }^{\circ} \mathrm{C} / \mathrm{min}$ and then at $\sim 6{ }^{\circ} \mathrm{C} / \mathrm{min}$ until the end. Diffraction data were collected with an acquisition time of $20 \mathrm{~s}$ throughout the heating by using the Mythen position sensitive detector. Data collection was stopped at $\sim 800{ }^{\circ} \mathrm{C}$ due to reaction between the sample and capillary. The wavelength and instrumental parameters were determined by using data for the NIST 640c Si standard reference material. In situ NPD experiments were performed at the high-intensity neutron powder diffractometer, Wombat, ${ }^{25}$ at ANSTO over a $2 \theta$ range $\left(16^{\circ}-136^{\circ}\right)$. The solid-state and sol-gel samples were measured by using neutron wavelengths of $2.41656(7)$ and 2.41580(7) A, respectively. The precursors were packed in cylindrical Pt cans, which were then heated in a high-temperature furnace (ILL type, niobium element vacuum furnace) equipped with a $\mathrm{Pt}$ tube insert. The solid-state sample was heated from room temperature to $300{ }^{\circ} \mathrm{C}$ at $10{ }^{\circ} \mathrm{C} / \mathrm{min}$, while the sol-gel sample was heated to the same temperature at $5{ }^{\circ} \mathrm{C} / \mathrm{min}$. They were then heated to $900{ }^{\circ} \mathrm{C}$ at $5{ }^{\circ} \mathrm{C} / \mathrm{min}$ and annealed for $6 \mathrm{~h}$, after which the furnace 
(a)

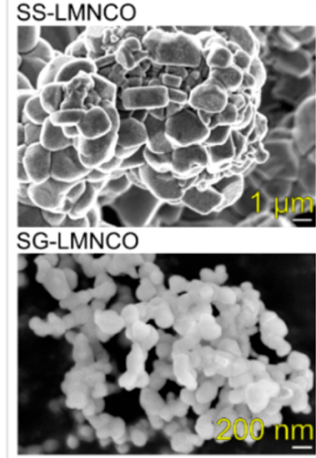

(c)

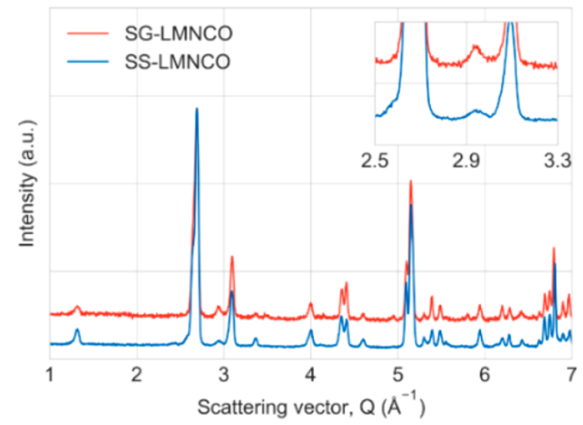

(b)

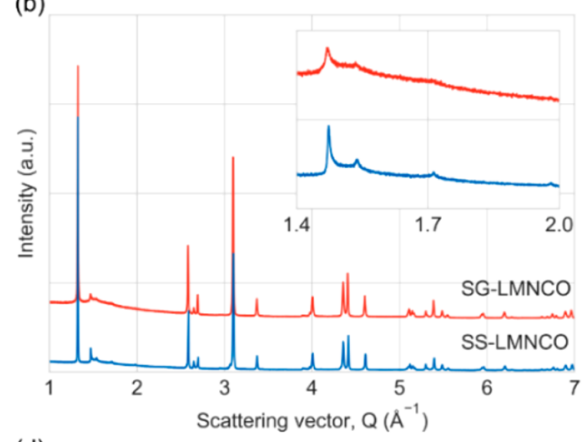

(d)

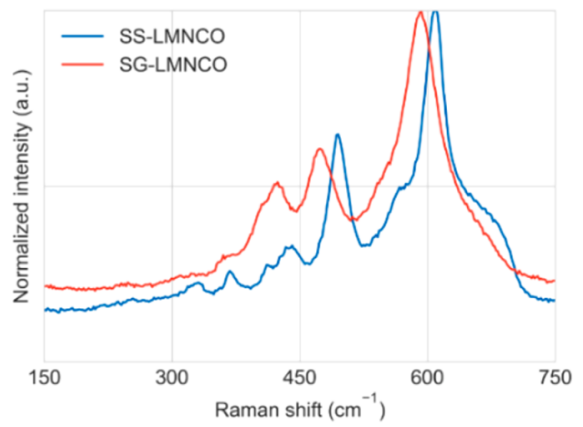

Figure 2. (a) SEM images (scale bars represent $1 \mu \mathrm{m}$ and $200 \mathrm{~nm}$ for SS-LMNCO and SG-LMNCO, respectively). Stack plots of (b) X-ray and (c) neutron diffraction patterns of the LMNCO samples (intensities are normalized to highest values) along with their (d) Raman spectra. The insets in (b) and (c) show a $Q$-space region with superstructure reflections.

was allowed to cool. Diffraction data were recorded every minute during the thermal treatment. The wavelength and the instrumental parameters were determined by using the data for the NIST $660 \mathrm{~b}$ $\mathrm{La}^{11} \mathrm{~B}_{6}$ standard reference material.

Instrumental parameters of the diffractometers were determined by Pawley refinement ${ }^{26}$ of the corresponding unit cells against data collected from the standard reference materials. Refinement of the hexagonal $(R \overline{3} m)$ and monoclinic $(\mathrm{C} 2 / \mathrm{m})$ unit cell parameters of the samples against $\mathrm{X}$-ray diffraction data was performed by using TOPAS Academic (V6) software. ${ }^{27}$ The monoclinic cell is a supercell of the hexagonal cell, and they are related via the following equation, where $\bar{a}, \bar{b}$, and $\bar{c}$ are the unit cell parameters.

$$
\left(\begin{array}{lll}
\bar{a} & \bar{b} & \bar{c}
\end{array}\right)_{C 2 / m}=\left(\begin{array}{lll}
\bar{a} & \bar{b} & \bar{c}
\end{array}\right)_{R \overline{3} m} \cdot\left(\begin{array}{lll}
-2 & 0 & 2 / 3 \\
-1 & -3 & 1 / 3 \\
0 & 0 & 1 / 3
\end{array}\right)
$$

Refinement (Rietveld ${ }^{28,29}$ ) of the LMNCO structures against X-ray and neutron diffraction data was performed with FAULTS ${ }^{30}$ and TOPAS, respectively. FAULTS facilitates the refinement of stacking faulted structures, thereby enabling an investigation of the degree of faulting within the structure in addition to other structural parameters. The single-phase stacking-faulted LMNCO structure model was obtained by modifying a previously reported $\mathrm{Li}_{2} \mathrm{MnO}_{3}$ structure ${ }^{31}$ to the LMNCO structure and approximating the TM species to $\mathrm{Mn}$ (i.e., $\left.\mathrm{Li}_{1.2} \mathrm{Mn}_{0.54} \mathrm{Ni}_{0.13} \mathrm{Co}_{0.13} \mathrm{O}_{2}=\mathrm{Li}_{1.2} \mathrm{Mn}_{0.8} \mathrm{O}_{2}\right)$, to avoid overparametrization. The difference between the TM electronic charges before and after this approximation is $\sim 5.8 \%$ and therefore is reasonable. For SSLMNCO, a two-phase model comprising of stacking-faulted $\mathrm{Li}_{2} \mathrm{MnO}_{3}{ }^{31}$ and $\mathrm{LiNi}_{0.33} \mathrm{Mn}_{0.33} \mathrm{Co}_{0.33} \mathrm{O}_{2}{ }^{10}$ phases was used, with the latter being incorporated as a background phase. Refinements against neutron diffraction data were performed without using stackingfaulted structure models. The single-phase structure model was obtained by modifying the LMNCO structure model reported by Whitfield et al. ${ }^{14}$ to fit the stoichiometry of the LMNCO samples in this study. Multiphase LMNCO structure refinements were performed by using $\mathrm{Li}_{2} \mathrm{MnO}_{3}{ }^{9}$ and $\mathrm{LiNi}_{0.33} \mathrm{Mn}_{0.33} \mathrm{Co}_{0.33} \mathrm{O}_{2}{ }^{10}$ structures, similar to conventional multiphase Rietveld refinements.
Additional details of the refinement procedures and the refined values are provided in the Supporting Information, sections S6 and S7. Crystallographic structures were visualized by using the VESTA software. ${ }^{32}$ It should be noted that diffraction data have been plotted in terms of the reciprocal space scattering vector, $Q\left(\AA^{-1}\right)$, to facilitate direct comparison between the different data sets. $Q$ is related to the scattering angle $(2 \theta)$ by $Q=(4 \pi \sin \theta) / \lambda$, where $\lambda$ is the wavelength of incident radiation.

The magnetic properties were measured with a Quantum Design magnetic property measurement system (MPMS-XL). The temperature dependence of constant field DC magnetization was measured from 300 to $2 \mathrm{~K}$. Each sample was first cooled to $2 \mathrm{~K}$ in zero field, then a field of 100 Oe was applied, and data were collected between 2 and $300 \mathrm{~K}$ (zero-field-cooling mode, ZFC). The sample was then cooled under the same applied field from 300 to $2 \mathrm{~K}$, while magnetization was measured (field-cooling mode, FC). Isothermal magnetization curves were measured at $5 \mathrm{~K}$ in magnetic fields up to \pm 50000 Oe. The temperature dependent sinusoidally varied (AC) susceptibility $\chi=\chi^{\prime}+\mathrm{i} \chi^{\prime \prime}$, where $\chi^{\prime}$ is the in-phase component and $\chi^{\prime \prime}$ is the out-of-phase component of the AC susceptibility, was measured in an AC magnetic field of 4 Oe at various frequencies $(1.7,17$, and $170 \mathrm{~Hz}$ ) within the temperature range 250 to $2 \mathrm{~K}$. The inverse magnetic susceptibility curves were fitted to the Curie-Weiss law $(\chi=$ $C /(T-\theta)$, where $C$ is the Curie constant, $T$ is the temperature, and $\theta$ is the Curie-Weiss temperature) by the SciPy ${ }^{33}$ "curve_fit" optimization function.

Raman spectra were measured on a Renishaw InVia Raman microscope with an excitation wavelength of $532 \mathrm{~nm}$ over the range 1000 to $100 \mathrm{~cm}^{-1}$. Prior to the measurements, instrument calibration was performed by using the internal $\mathrm{Si}$ reference standard (520.6 \pm $0.1 \mathrm{~cm}^{-1}$ ). To improve the data quality, ten spectra with an individual $15 \mathrm{~s}$ exposure time were averaged for each sample.

Galvanostatic cycling was conducted by using Swagelok cells prepared in an argon-filled glovebox in half-cell configuration. The working electrode was prepared by mixing $\sim 75 \mathrm{wt} \%$ of the active material (LMNCO) and $\sim 25$ wt \% of carbon black (Super P Conductive, Alfa Aesar, 99\%) with a mortar and pestle. This mixture was dried overnight in a vacuum oven inside the glovebox at $120^{\circ} \mathrm{C}$. 
(a)

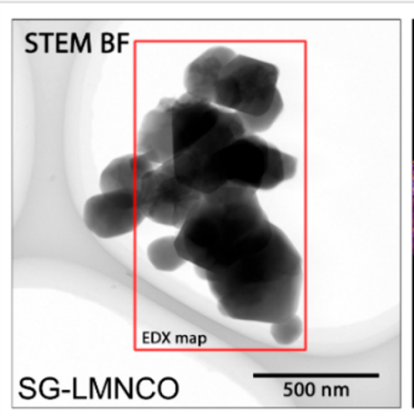

(b)
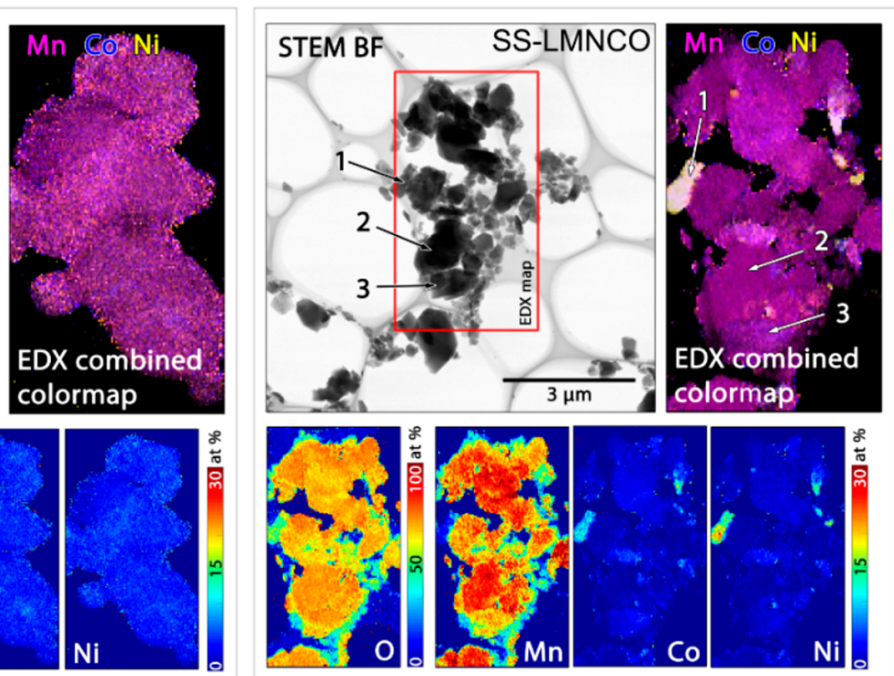

Figure 3. Bright field (BF) STEM data with EDX maps of (a) SG-LMNCO and (b) SS-LMNCO. Quantified elemental maps are shown at the bottom.

Half-cells were prepared by using Li metal as a counter electrode and two glass fiber separators (dried at $150{ }^{\circ} \mathrm{C}$ for $6 \mathrm{~h}$ in a vacuum inside the glovebox), with a standard electrolyte solution of $1 \mathrm{M} \mathrm{LiPF}_{6}$ in ethylene carbonate (EC):diethyl carbonate (DEC) (1:1 vol \%) (Sigma-Aldrich, 99\%). The cells were cycled on the Land BT2000 battery testing system between 2.0 and $4.8 \mathrm{~V}$ at $5 \mathrm{~mA} / \mathrm{g}$ under ambient conditions $\left(\sim 22{ }^{\circ} \mathrm{C}\right)$, with an initial resting step at the open circuit voltage $(\mathrm{OCV})$ for $5 \mathrm{~h}$.

\section{RESULTS AND DISCUSSION}

Morphology, Stoichiometry, and Long-Range Crystallographic Structure. The as-synthesized samples noticeably differed in their morphology (Figure 2a). The solid-state LMNCO sample (SS-LMNCO) had heterogeneous secondary particles several micrometers in size formed from tightly packed primary particles of varying sizes, with particles at the surface $(\sim 1-3 \mu \mathrm{m})$ larger than interior ones $(\sim 0.5-1 \mu \mathrm{m})$. The sol-gel sample (SG-LMNCO) was predominantly composed of loosely bound homogeneously shaped particles, 100-200 nm in size. The Li:Mn:Ni:Co stoichiometry was determined by inductively coupled plasma optical emission spectroscopy (ICP-OES) analysis to be $1.216(13): 0.533(19): 0.125(9): 0.12(1)$ and 1.2101(33):0.536(16):0.128(34):0.124(31) for SS-LMNCO and SG-LMNCO, respectively (Table $\mathrm{S} 1$ ). The two compositions are therefore comparable, with a Li content slightly higher than expected due to the excess used in synthesis.

The diffraction data in Figure 2 reveal an overall structural similarity between the samples, with the exception of the superstructure reflections (insets in Figures $2 b, c$ ). The parent hexagonal $(R \overline{3} m)$ unit cells of the two materials were compared by using Pawley analysis of the X-ray diffraction (XRD) data. The unit cell parameters of the samples show slight differences- $0.16 \%$ and $0.04 \%$ for $a(b)$ and $c$ lattice parameters, respectively-and are tabulated in Table S2. The $c / 3 a$ value, a measure of the deviation of the hexagonal lattice from the ideal cubic close-packed (ccp) arrangement $(c / 3 a=$ 1.633 ), is comparable (difference of $\sim 0.2 \%$ ) between the samples and to other layered $\mathrm{LiNi}_{x} \mathrm{Mn}_{y} \mathrm{Co}_{1-x-y} \mathrm{O}_{2}$ systems, ${ }^{34}$ signifying that the samples have a well-crystallized layered structure. However, the presence of superstructure reflections and the different peak amplitude of the 108 and 110 reflections $\left(R \overline{3} m\right.$ symmetry, observable at $\sim 4.5 \AA^{-1}$ ) unambiguously evidence a monoclinic symmetry. Pawley refinement of a monoclinic $(\mathrm{C} 2 / \mathrm{m})$ unit cell is tabulated in Table S3.

Despite the close composition and bulk crystallographic structure of the two samples, the differences in Raman spectra of the samples (Figure 2d) are quite distinct. However, as the deconvolution of the spectra is complicated by the elemental composition, structural disorder, and microstructural differences, conclusions that can be drawn from it are limited. A qualitative analysis of the spectra, presented in the Supporting Information, section 3, points toward incomparable local TMO coordination environments in the samples, with the SSLMNCO sample suggesting the possible existence of multiple phases. Taken together, these results establish that the two LMNCO samples have comparable stoichiometry and longrange average structure but dissimilar local structural features.

Differences in Local TM Distribution. As the two LMNCO models have identical average structures, characterization techniques sensitive to the local (Li-)TM ordering must be employed to investigate the structural differences. Here, the TM distributions of the samples were probed at different length scales by using scanning transmission electron microscopy-X-ray energy dispersive spectroscopy (STEMEDX) and magnetic measurements. EDX mapping was performed at microscopic length scales to probe the chemical homogeneity of the samples. The SG-LMNCO map revealed a homogeneous distribution of TMs without microscopic segregation of any species, including oxygen which was uniformly distributed and close to the expected $\sim 71 \mathrm{~mol} \%$. The quantified values for the constituent elements are comparable to the composition of LMNCO (Tables S4 and S5). On the other hand, the SS-LMNCO sample is inhomogeneous and composed of at least three chemically distinct particle types or regions, which are shown in Figure $3 \mathrm{~b}$ (and highlighted in Figure S4), with the corresponding compositions tabulated in Table S5. Region 1 is predominantly composed of $\mathrm{Ni}$ and $\mathrm{Co}$. The $\mathrm{O}$ content was quantified to be $\sim 62 \%$, which is lower than that of $\mathrm{LiNi}_{0.33} \mathrm{Mn}_{0.33} \mathrm{Co}_{0.33} \mathrm{O}_{2}$ (66\%). Region 2, almost devoid of $\mathrm{Ni}$ and $\mathrm{Co}$, has $\mathrm{O}$ and 
(a)

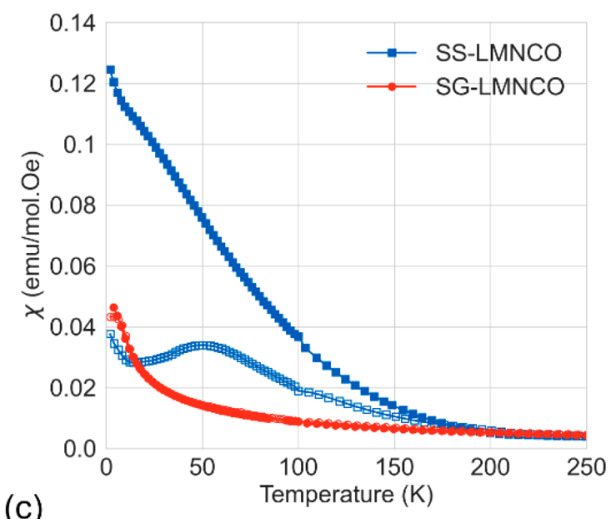

(c)

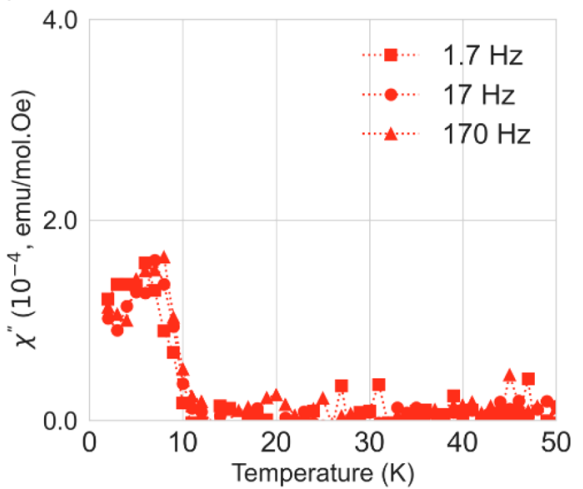

(b)

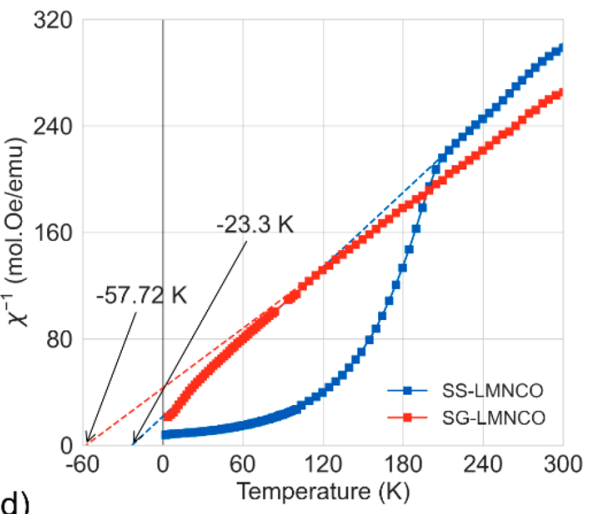

(d)

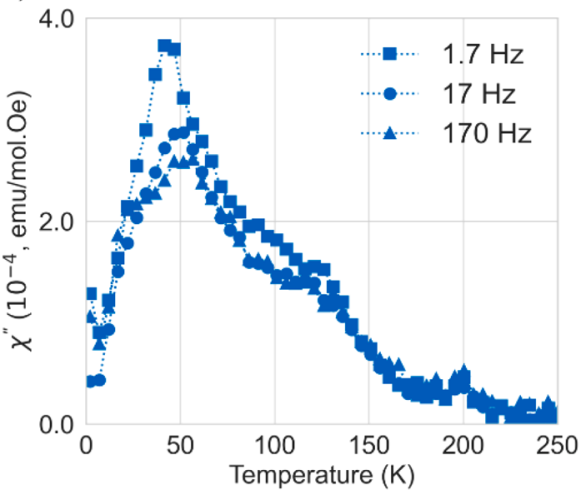

Figure 4. (a) Temperature-dependent constant field (DC) magnetic susceptibility $(\chi)$ of the samples. Field-cooled (FC) and zero-field-cooled (ZFC) susceptibilities are shown as filled and empty symbols, respectively. (b) Reciprocal FC susceptibilities with their fits (dashed lines) to the Curie-Weiss law. Temperature dependences of the imaginary/out-of-phase magnetic susceptibility ( $\left.\chi^{\prime \prime}\right)$ of SG-LMNCO (c) and SS-LMNCO (d). Points are connected by lines for clarity.

Mn contents of $\sim 72.5 \%$ and $\sim 25 \%$, which are comparably close to that of $\mathrm{Li}_{2} \mathrm{MnO}_{3}$. Region 3 has a considerable amount of all species, with the $\mathrm{Mn}$ and $\mathrm{O}$ values conforming to the values expected from LMNCO. However, the $\mathrm{Ni}$ and $\mathrm{Co}$ values are lower than expected. This suggests either that the $\mathrm{Li}_{2} \mathrm{MnO}_{3}$-like phase is present in excess and the composition of the $\mathrm{Li}-\mathrm{Ni}-\mathrm{Mn}-\mathrm{Co}-\mathrm{O}$ phase is manganese-deficient or that the $\mathrm{Li}_{2} \mathrm{MnO}_{3}$-like phase is overrepresented within the area probed. These results suggest that the sample could be composed of $\mathrm{Li}_{2} \mathrm{MnO}_{3}$ and $\mathrm{Li}\left[\mathrm{Ni}_{y} \mathrm{Co}_{z} \mathrm{Mn}_{1-y-z}\right] \mathrm{O}_{2}(y, z \geq$ 0.33 ) phases integrated heterogeneously, ranging from atomicscale intergrowths to segregated $\mathrm{Li}_{2} \mathrm{MnO}_{3}$ and Li$\left[\mathrm{Ni}_{y} \mathrm{Co}_{z} \mathrm{Mn}_{1-y-z}\right] \mathrm{O}_{2}$ particles. Considering that the ICP-OES results establish the conformity of the overall stoichiometry to the expected value, SS-LMNCO may be represented as $(x) \mathrm{Li}_{2} \mathrm{MnO}_{3} \cdot(1-x) \mathrm{Li}\left[\mathrm{Ni}_{y} \mathrm{Co}_{z} \mathrm{Mn}_{1-y-z}\right] \mathrm{O}_{2}$ where $0.5 \leq x \leq$ 1 and $y, z \geq 0.33$. This agrees well with the Raman spectra, which show the peaks for pure $\mathrm{Li}_{2} \mathrm{MnO}_{3}$ and $\mathrm{LiNi}_{0.33} \mathrm{Mn}_{0.33^{-}}$ $\mathrm{Co}_{0.33} \mathrm{O}_{2}$ phases (Figure S3). With the EDX data clearly evidencing different TM distributions in the two samples at a microscopic scale, magnetic measurements were performed to probe the distribution within the bulk.

The temperature-dependent DC magnetic susceptibilities $(\chi)$ of the LMNCO samples show pronounced differences, as seen in Figure 4a. In SG-LMNCO, the ZFC and FC curves trace the same path until $\sim 8 \mathrm{~K}$, where the plots diverge and a cusp is visible in the ZFC susceptibility (Figure S5). This is typical of spin glass systems that are in a state of quenched magnetic disorder due to the presence of randomly oriented magnetic moments. ${ }^{35,36}$ Comparable behavior is observed in
$\mathrm{LiNi}_{0.33} \mathrm{Mn}_{0.33} \mathrm{Co}_{0.33} \mathrm{O}_{2}$, where the spin glass behavior is realized through configurational disorder facilitated by a random distribution of TMs in the TM layer. ${ }^{36}$

This reasoning may be extended to explain the magnetic response of SG-LMNCO, where a structural configuration with random distribution of TM ions (with respect to $\mathrm{Li}$ ) precludes the formation of magnetic ordering within the sample above 2 $\mathrm{K}$. The layered (rock salt) structure with its stacking of twodimensional triangular edge-sharing planes imparts the geometric frustration necessary to realize a spin glass state. An empirical criterion for the realization of a spin glass with magnetic frustration is that the $|\theta| / T_{\mathrm{f}}$ value should be greater than 10 , where $\theta$ is the Curie-Weiss temperature and $T_{\mathrm{f}}$ is the freezing temperature. ${ }^{35}$ As shown in Figure $4 \mathrm{~b}$, the CurieWeiss temperature for SG-LMNCO is $-57.72 \mathrm{~K}$, which results in $|\theta| / T_{\mathrm{f}}$ of 7.21 , suggesting that SG-LMNCO, although not a perfect spin glass system, is close to a state of configurational disorder with respect to the TMs. The out-of-phase $\left(\chi^{\prime \prime}\right)$ component of the AC magnetic susceptibility of SG-LMNCO shows a frequency-dependent sharp onset of dissipation at $\sim 8$ $\mathrm{K}$ (Figure 4c). This onset is found to shift toward lower temperature with lower frequency, as typical of spin glass systems, further evidencing the absence of magnetic/cation clustering in this sample. Therefore, the magnetic response of SG-LMNCO, in corroboration with the EDX results, does not provide evidence for any TM segregation in the structure. This conclusively rules out the existence of $\mathrm{Li}_{2} \mathrm{MnO}_{3}$ domains in the structure and suggests that SG-LMNCO is similar to the single-phase LMNCO model. 
The magnetic response of SS-LMNCO is more complex. The FC and ZFC curves diverge at $\sim 200 \mathrm{~K}$, and on further cooling, the FC curve increases strongly while the ZFC curve increases only slowly, displaying an antiferromagnetic-like transition at $\sim 50 \mathrm{~K}$. This divergent behavior of the ZFC-FC curves is characteristic of cluster glass systems composed of phase-separated magnetic domains, ${ }^{37,38}$ suggesting that SSLMNCO is a multiphase system. The presence of $\mathrm{Li}_{2} \mathrm{MnO}_{3}$ phase is revealed by the antiferromagnetic transition at $\sim 50 \mathrm{~K}$ in the ZFC curve, which is characteristic of this phase (Figure S6). The significant increase of magnetic susceptibility on continued cooling is due to different types of short-range magnetic ordering, including ferromagnetic ordering with a $180^{\circ} \mathrm{Ni}^{2+}{ }_{\text {Lilayer }}-\mathrm{O}-\mathrm{Mn}^{4+}{ }_{\text {TMlayer }}$ interaction, which can be introduced by $\mathrm{Ni}^{2+}$ in the $\mathrm{Li}$ layer in $\mathrm{Li}\left[\mathrm{Ni}_{y} \mathrm{Co}_{z} \mathrm{Mn}_{1-y-z}\right] \mathrm{O}_{2} /$ $\mathrm{LiNi}_{0.33} \mathrm{Mn}_{0.33} \mathrm{Co}_{0.33} \mathrm{O}_{2}$ domains. ${ }^{36}$ On the basis of Goodenough's rules, the antiferromagnetic $\mathrm{Mn}-\mathrm{O}-\mathrm{Li}-\mathrm{O}-\mathrm{Mn}$ superexchange interaction in the $\mathrm{Li}_{2} \mathrm{MnO}_{3}$ domains is considered the dominant mechanism. ${ }^{39}$ Similar observations for the compositionally similar (commercial) $\mathrm{Li}_{1.2} \mathrm{Mn}_{0.55} \mathrm{Ni}_{0.15} \mathrm{Co}_{0.10} \mathrm{O}_{2}$ were reported by Mohanty et al., ${ }^{13}$ including a magnetic transition at $\sim 50 \mathrm{~K}$ in the $\mathrm{ZFC}$ curve. The slight hysteresis observed in the $M-H$ curve for SSLMNCO may be attributed to the increased magnetization, as opposed to SG-LMNCO where no hysteresis is observed (Figure S7). From the inverse susceptibility (FC) plot in Figure $4 \mathrm{~b}$, it is evident that SS-LMNCO follows the CurieWeiss law until $\sim 200 \mathrm{~K}$, below which it begins to deviate due to the onset of magnetic (ferromagnetic and antiferromagnetic) ordering in different domains. In the AC susceptibility curves (Figure $4 \mathrm{~d}$ ), the broad maximum of the $\chi^{\prime \prime}$ component around $50 \mathrm{~K}$ represents dissipation in the vicinity of the expected phase transition and further confirms the existence of antiferromagnetic $\mathrm{Li}_{2} \mathrm{MnO}_{3}$ domains in the structure. Additionally, a feature is also observed around $200 \mathrm{~K}$ in the $\chi^{\prime \prime}$ component, signifying the dissipation of ferromagnetic or ferrimagnetic clusters. The Curie-Weiss fit of the samples and calculation of the effective magnetic moments are provided in the Supporting Information (section S5.1).

Structural Analysis Using Powder Diffraction Data. The structural differences highlighted by the EDX and magnetic measurements should be visible in diffraction data, the analysis of which can further corroborate the results obtained thus far. Considering the different X-ray and neutron scattering of constituent elements (Table S7) and risk of model overparametrization, structural refinements against powder diffraction data must be constrained to produce statistically reliable results. Complementary techniques like magnetic measurements are useful in guiding this constraint. Therefore, refinements of stacking-fault incorporated singleand multiphase LMNCO structure models were performed against SG-LMNCO and SS-LMNCO XRD data, respectively, by using FAULTS. ${ }^{30}$ For SS-LMNCO, refinements were performed using faulted- $\mathrm{Li}_{2} \mathrm{MnO}_{3}$ and $\mathrm{LiNi}_{0.33} \mathrm{Mn}_{0.33} \mathrm{Co}_{0.33} \mathrm{O}_{2}$ phases, with the latter incorporated as background. As seen in Figure 5, satisfactory fits are obtained, and the degree of faulting (explained in the Supporting Information, section S6.2) in SS-LMNCO and SG-LMNCO is calculated to be $25.77(10) \%$ and $48.15(20) \%$, respectively. While satisfactory, the fit is less good for SS-LMNCO due to the variation of faulting within the structure as previously reported for LMNCO and other Li-rich layered oxides. ${ }^{7,16}$ This variation of faulting implies that this material cannot be considered as a (a)

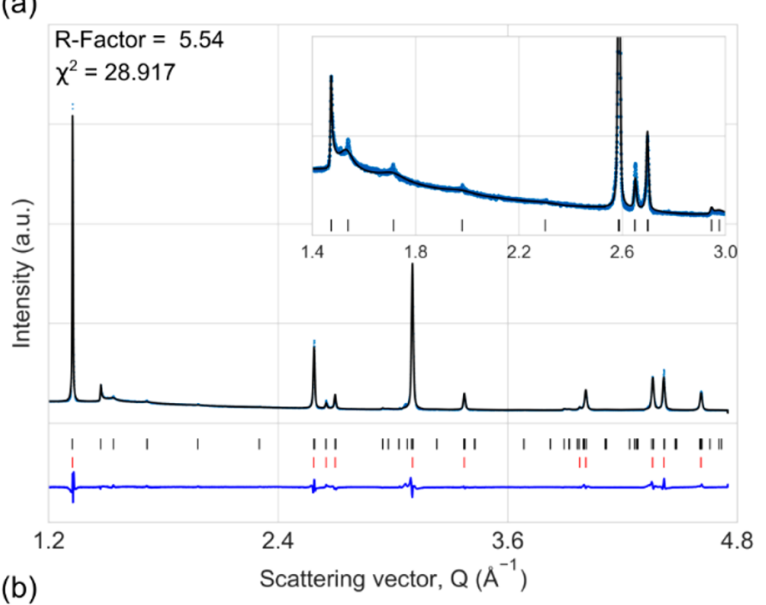

(b)

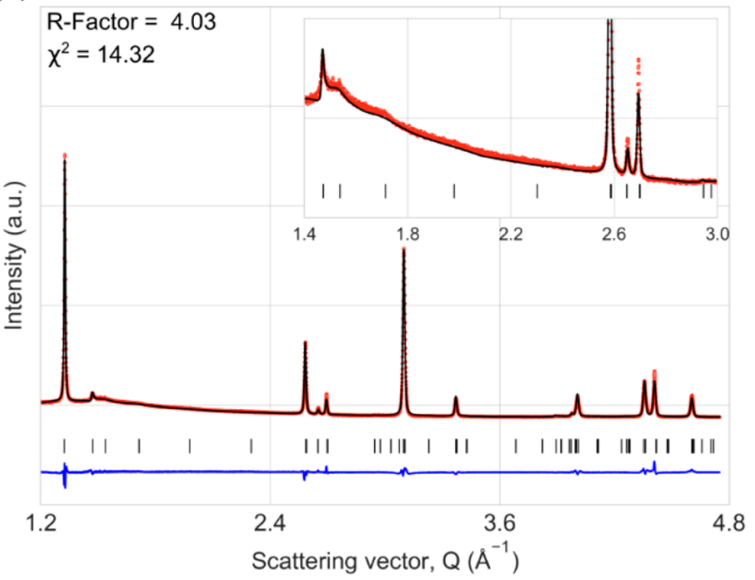

Figure 5. Refinement plots of stacking faulted structure models against XRD data. The observed and calculated intensities are shown as colored circles and black lines, respectively. The difference curve is shown in blue and the positions of the Bragg reflections as vertical tick markers. In (a) the black and red markers denote $\mathrm{Li}_{2} \mathrm{MnO}_{3}$ and $\mathrm{LiNi}_{0.33} \mathrm{Mn}_{0.33} \mathrm{Co}_{0.33} \mathrm{O}_{2}$ phases, respectively. In (b), the markers denote the LMNCO phase. The definitions of the $R$-Factor and $\chi^{2}$ can be found in the FAULTS manual.

"single phase", even if in practice a "single" LMNCO phase model is used for refinements. For SS-LMNCO, the percentage area of the phases (indicative of the phase composition) after refinement was $\sim 65 \%$ and $\sim 35 \%$ for $\mathrm{Li}_{2} \mathrm{MnO}_{3}$ and $\mathrm{LiNi}_{0.33} \mathrm{Mn}_{0.33} \mathrm{Co}_{0.33} \mathrm{O}_{2}$, respectively, indicating an excess of $\mathrm{Li}_{2} \mathrm{MnO}_{3}$, further corroborating the EDX data where the phase was found to be overrepresented. That it is also in excess from modeling of the diffraction data implies that the result obtained from EDX is likely applicable to the bulk. SG-LMNCO and SS-LMNCO XRD data were also intentionally fit to the multi- and single-phase models, respectively, to confirm the refinement results. This resulted in chemically invalid models in either case, thereby justifying the initial choice of structure models. Refinement of the structure models against the neutron diffraction data offered further validation of the results, in addition to confirming small amounts of $\mathrm{Li}^{+}-$ $\mathrm{Ni}^{2+}$ interlayer mixing in the samples. The structure refinement methodology and the refined values are provided in the Supporting Information, section S6 (X-ray) and section S7 (neutron). The results obtained thus far confirm the initial hypothesis that the crystallography of LMNCO is a consequence of synthesis pathway, given the identical composition and heat treatment. To investigate the underlying 
(a) SG-LMNCO

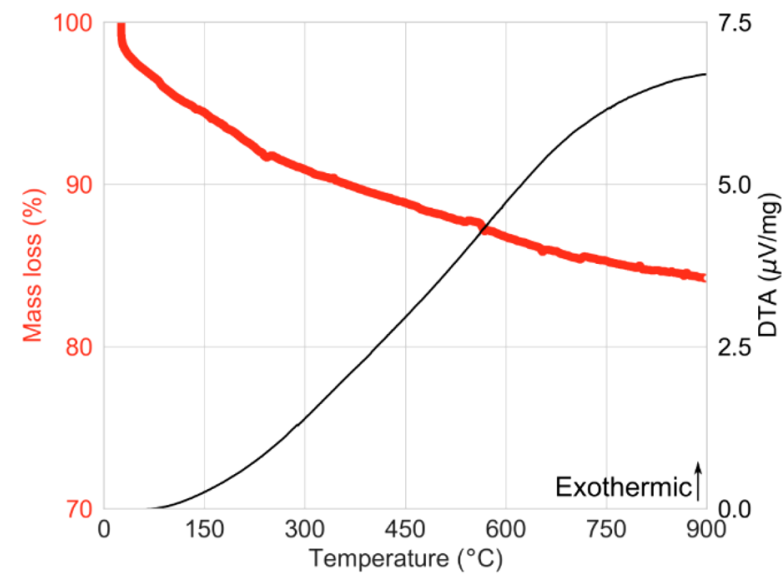

(c)

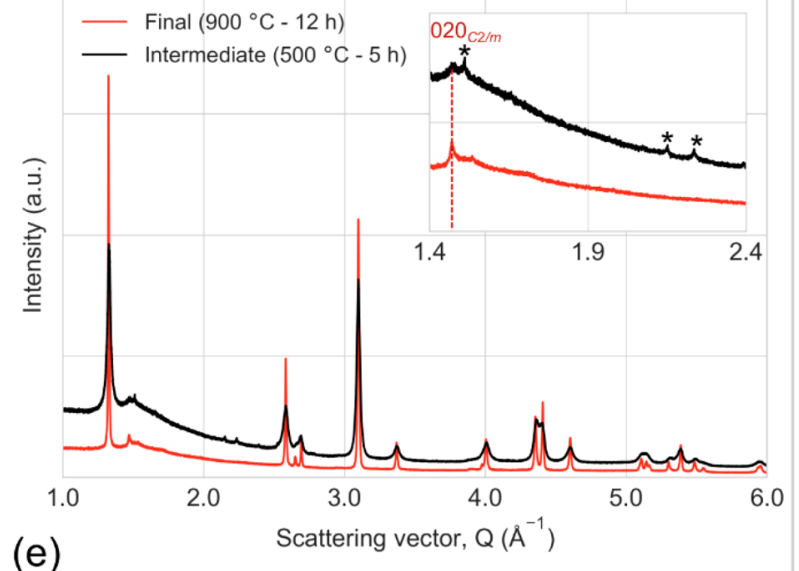

(e)

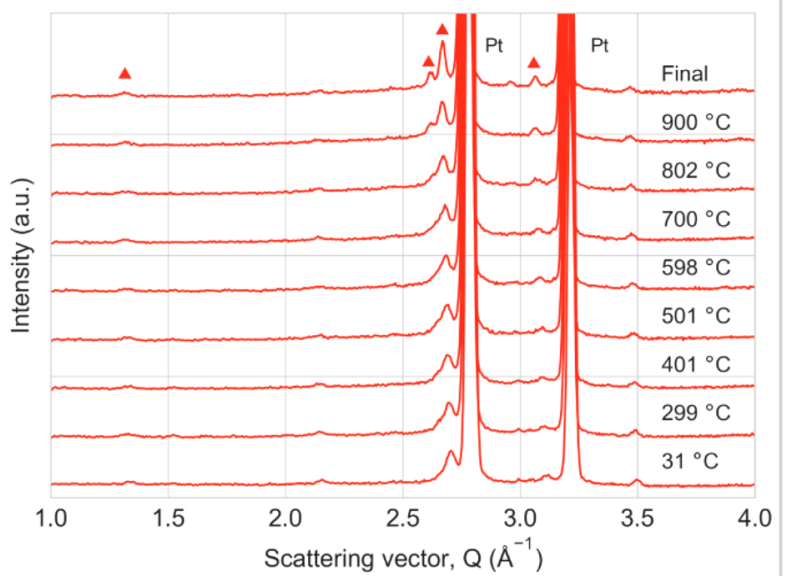

(b) SS-LMNCO

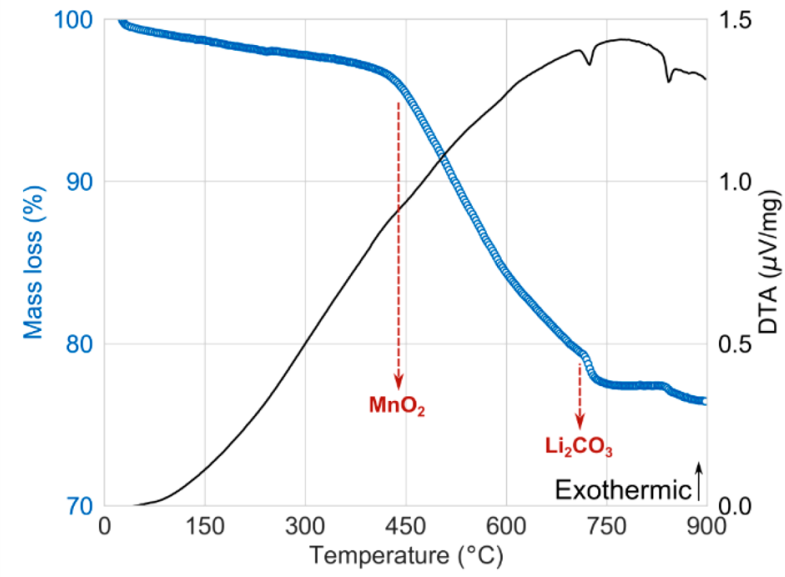

(d)

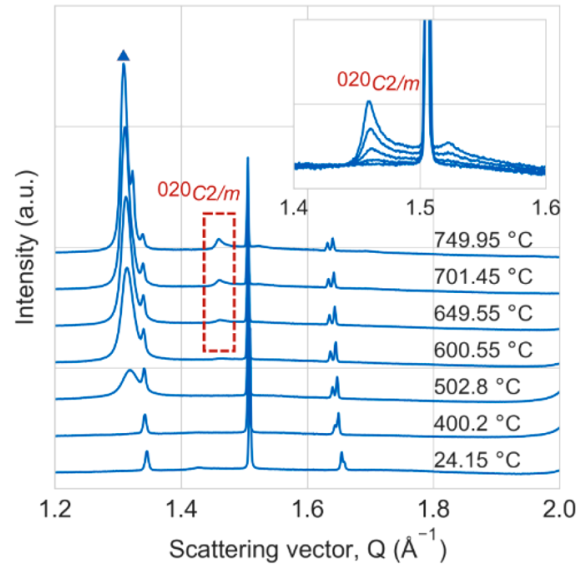

(f)

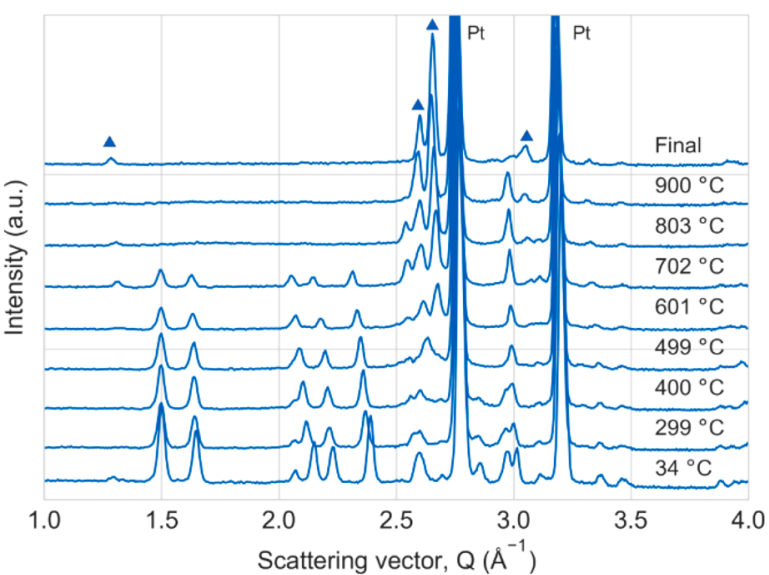

Figure 6. TG-DTA plots of (a) SG-LMNCO and (b) SS-LMNCO precursors. (c) Ex situ XRD data of the SG-LMNCO precursor after preheating and final annealing. The $020(\mathrm{C} 2 / \mathrm{m})$ superstructure reflection is highlighted in the inset in $(\mathrm{c})$. The asterisk denotes reflections from precursors due to incomplete synthesis reactions. (d) In situ XRD data of the SS-LMNCO precursor at selected temperatures (offset in $y$ ), with the 020 reflection highlighted in the inset (plots are overlaid in the inset). In situ NPD data of the (e) SG-LMNCO and (f) SS-LMNCO precursors (offset in $y$ ) at selected temperatures. In (d), (e), and (f), the LMNCO phase is shown with colored triangular markers. Fully indexed diffraction patterns of the precursor mix (before the in situ heating) are shown in Figures S12 and S13.

reasons for these differences, the structures were studied during their synthesis through thermal analysis and in situ powder diffraction.

In Situ Investigation of the Material Synthesis. The thermal gravimetric-differential thermal analysis (TG-DTA) and in situ diffraction data for LMNCO precursors are shown in Figure 6. As seen in Figure 6a, the gradual weight loss due to the decomposition of organic matter is all that occurs during the final heating.

This suggests that the LMNCO phase must have already formed during the intermediate annealing step. The thermal response of the as-synthesized sol-gel precursor upon heating to $550{ }^{\circ} \mathrm{C}$ (representative of the intermediate heating step) is provided in Figure S11. The response can be divided into two 
stages. The first stage centered around $175{ }^{\circ} \mathrm{C}$ arises from the loss of aqueous and acidic species, and as the temperature reaches $450{ }^{\circ} \mathrm{C}, \sim 60 \%$ mass loss has occurred. Between 450 and $500{ }^{\circ} \mathrm{C}$, there is a mass loss of about $35 \%$ because of the decomposition of organic matter and its removal as gaseous products. This decomposition proceeds through breaking of chemical bonds and is highly exothermic. Although in situ diffraction studies are required to understand the crystallization pathway, comparing the ex situ XRD patterns (Figure 6c) of the intermediate and final SG-LMNCO samples, it is clear that the LMNCO phase has already formed after the intermediate heating, with the crystallization happening concomitantly with the organic matter decomposition. Additional reflections in the intermediate sample XRD data (highlighted with asterisks in Figure $6 c$, inset) indicate that the synthesis is not complete. Superstructure reflections are also already visible in the intermediate sample, signifying some degree of Li-TM ordering. On the basis of these results, it can be understood that during final annealing step the crystallinity of the alreadyformed LMNCO phase increases through atomic ordering, together with the growth of crystallites. As the crystallization occurs from a metal-citrate matrix with a homogeneous distribution of cations, the probability for $\mathrm{Mn}$ to preferentially cluster around $\mathrm{Li}$ is reduced, hindering the formation of $\mathrm{Li}_{2} \mathrm{MnO}_{3}$ domains and subsequent phase segregation in the structure. In contrast to SS-LMNCO (Figure $6 \mathrm{~d}$, inset), the intensity of the $020(\mathrm{C} 2 / \mathrm{m})$ superstructure reflection in the forming SG-LMNCO material does not increase substantially over the course of the final annealing, suggesting an increased kinetic barrier toward Li-TM ordering.

Figure $6 \mathrm{~b}$ shows the TG-DTA and in situ diffraction data during heating of the SS-LMNCO precursor mix containing $\mathrm{Li}_{2} \mathrm{CO}_{3}, \mathrm{MnO}_{2}, \mathrm{NiO}$, and $\mathrm{Co}_{3} \mathrm{O}_{4}$. Indexed diffraction data of the precursor mix prior to heating are provided in Figures S12 and S13. The TG-DTA plots reveal that the synthesis proceeds through three stages corresponding to the decomposition of $\mathrm{MnO}_{2},{ }^{40} \mathrm{Li}_{2} \mathrm{CO}_{3}{ }^{41}$ and $\mathrm{Co}_{3} \mathrm{O}_{4}{ }^{42}$ The mass loss at $\sim 450{ }^{\circ} \mathrm{C}$ corresponds to the onset of the decomposition of $\mathrm{MnO}_{2}$ into $\mathrm{Mn}_{2} \mathrm{O}_{3}$ accompanied by $\mathrm{O}_{2}$ gas evolution. The Li-rich phase emerges between 500 and $600{ }^{\circ} \mathrm{C}$, as seen in both the $\mathrm{X}$-ray $\left(001_{C 2 / m}\right.$ at $\left.\sim 1.3 \AA^{-1}\right)$ and neutron $\left(1 \overline{3} 1_{C 2 / m}\right.$ and $200_{C 2 / m}$ at $\sim 2.7 \AA^{-1}$ ) data, and continues to grow with heating. At these temperatures, the $\mathrm{Co}_{3} \mathrm{O}_{4}$ and $\mathrm{NiO}$ reflections are unaffected whereas the intensities of the $\mathrm{Li}_{2} \mathrm{CO}_{3}$ and $\mathrm{MnO}_{2}$ reflections decrease substantially, as shown in the Figure S14, suggesting that the Li-rich phase is $\mathrm{Li}_{2} \mathrm{MnO}_{3}$. Starting at $\sim 620^{\circ} \mathrm{C}$, the $020_{C 2 / m}$ superstructure reflection is clearly seen in the XRD data (Figure $6 \mathrm{~d}$, inset), evidencing $\mathrm{Li}-\mathrm{Mn}$ ordering in the $\mathrm{Li}_{2} \mathrm{MnO}_{3}$ phase. The asymmetric broadening of these reflections is also clearly visible as they grow, indicating the presence of stacking faults in the $\mathrm{Li}_{2} \mathrm{MnO}_{3}$ phase. As the temperature approaches $700{ }^{\circ} \mathrm{C}$, the $\mathrm{Co}_{3} \mathrm{O}_{4}$ and $\mathrm{NiO}$ reflections begin to lose intensity, indicating their entry into the reaction matrix, and on further annealing, the $\mathrm{Ni}$ and $\mathrm{Co}$ species are incorporated into the $\mathrm{Li}_{2} \mathrm{MnO}_{3}$ phase, leading to the formation of the $\mathrm{LMNCO}$ phase. Note that $\mathrm{Li}_{2} \mathrm{CO}_{3}$ is present in the XRD data $\left(\right.$ at $\sim 1.5 \AA^{-1}$ ) at temperatures close to $750{ }^{\circ} \mathrm{C}$, which is higher than its melting point. This is because of the localized (non-uniform) heating of the hot-air blower used for the in situ XRD experiment. However, as seen in the EDX maps, the inhomogeneous contact between the precursors (that leads to varying diffusion lengths) results in the heterogeneous incorporation of $\mathrm{Ni}$ and $\mathrm{Co}$ into the
$\mathrm{Li}_{2} \mathrm{MnO}_{3}$ phase. This leads to the formation of $\mathrm{Li}_{2} \mathrm{MnO}_{3}$ and $\mathrm{Li}\left[\mathrm{Ni}_{y} \mathrm{Co}_{z} \mathrm{Mn}_{1-y-z}\right] \mathrm{O}_{2}(y, z \geq 0.33)$ phases that are integrated to varying degrees, ranging from crystallographic intergrowths (within a particle) to instances where they exist as different primary particles. Hence, SS-LMNCO has a multiphase LMNCO structure that may be represented as $(x) \mathrm{Li}_{2} \mathrm{MnO}_{3}$. $(1-x) \mathrm{Li}\left[\mathrm{Ni}_{y} \mathrm{Co}_{z} \mathrm{Mn}_{1-y-z}\right] \mathrm{O}_{2}$ where $0.5 \leq x \leq 1$ and $y, z \geq$ 0.33. Considering the above mechanism, it is clear that the specific crystallization pathway of SS-LMNCO will be dependent on the choice of precursors and temperatures at which they begin to react. This offers additional possibilities through which the crystallography can be controlled. Coprecipitation is another method to synthesize multi-cation systems like LMNCO, even more so than the solid-state method. In terms of precursor mixing, it represents an intermediate case (with separate $\mathrm{Li}$ and TM sources) between sol-gel and solid-state methods, which provide a high and low degree of mixing, respectively. As described in this work, in addition to the local cation ordering, the different synthesis routes can also affect the degree of structural integration between the two phases (as in the multiphase model). This has recently been shown to affect the structural and electrochemical properties of solid-state synthesized $\mathrm{Li}_{1.2} \mathrm{Mn}_{0.6} \mathrm{Ni}_{0.2} \mathrm{O}_{2}{ }^{43}$ and therefore may be thought to influence LMNCO as well.

The differences in synthesis routes are also reflected in the degree of faulting observed in the samples. The reduced stacking disorder in SS-LMNCO indicates increased periodicity in the $\mathrm{Li}-\mathrm{Mn}$ layer along the $c$ direction in the $\mathrm{Li}_{2} \mathrm{MnO}_{3}$ phase. This is achieved as the cation ordering involves only two species ( $\mathrm{Li}$ and $\mathrm{Mn}$ ), and therefore order between consecutive TM layers is thermodynamically favorable relative to SGLMNCO, where four cations ( $\mathrm{Li}$ with $\mathrm{Mn}, \mathrm{Ni}$, and $\mathrm{Co}$ ) are involved. This imparts more degrees of freedom and entropy drives SG-LMNCO toward a more disordered state. Additionally, the presence of organic matter may hinder the formation of a well-layered structure, as shown for sol-gel synthesized $\mathrm{Li}_{2} \mathrm{MnO}_{3}$ in our previous work. ${ }^{16}$

This work establishes that the phase composition of LMNCO varies significantly depending on the synthetic route. The samples in this work were synthesized by using identical final annealing protocols, and therefore the primary difference between the synthesis methods is the degree of precursor mixing. However, since limited heat treatment protocols were used, both structural forms could be metastable. This leads to questions concerning the most thermodynamically stable LMNCO configuration and its formation mechanism. Are there thermodynamic drivers for phase segregation, or does entropy stabilization driven by configurational disorder lead to solid solution-like single-phase structures? $?^{44}$ This is an important consequence of this study to consider when tailoring the design of electrode materials as different metastable configurations will result in different electrochemical responses. Furthermore, the anionic redox behavior of LMNCO has been explained based on the $\mathrm{Li}_{2} \mathrm{MnO}_{3}$ domains in the structure in several studies. ${ }^{12,45,46}$ However, the single-phase SG-LMNCO shows electrochemical and anionic redox behavior that is typical of LMNCO systems (Figure S15). This suggests that the anionic redox behavior is not dependent on the presence of $\mathrm{Li}_{2} \mathrm{MnO}_{3}$ domains. The figure also includes the first-cycle potential-capacity plots of SS-LMNCO. Although the profiles bear a qualitative resemblance to that of SG-LMNCO, the capacities are 
expectedly lower than that of SG-LMNCO, primarily because of the larger micrometer-sized particles and their heterogeneous morphology.

\section{CONCLUSION}

This work demonstrates that $\mathrm{Li}_{1.2} \mathrm{Mn}_{0.54} \mathrm{Ni}_{0.13} \mathrm{Co}_{0.13} \mathrm{O}_{2}$ (LMNCO) can exist in multiple nonequilibrium crystallographic forms, with the synthesis route being a major determinant. The solid-state synthesized LMNCO (SSLMNCO) crystallizes as a multiphase structure, with $\mathrm{Li}_{2} \mathrm{MnO}_{3}$ and $\mathrm{Li}\left[\mathrm{Ni}_{y} \mathrm{Co}_{z} \mathrm{Mn}_{1-y-z}\right] \mathrm{O}_{2}(y, z \geq 0.33)$ phases integrated to varying degrees ranging from crystallographic intergrowths to distinct particles. This is a consequence of the synthetic pathway, where the initial reaction between the $\mathrm{Li}_{2} \mathrm{CO}_{3}$ and $\mathrm{MnO}_{2}$ precursors forms $\mathrm{Li}_{2} \mathrm{MnO}_{3}$, after which Co and $\mathrm{Ni}$ are integrated into the structure heterogeneously resulting in $\mathrm{Li}\left[\mathrm{Ni}_{y} \mathrm{Co}_{z} \mathrm{Mn}_{1-y-z}\right] \mathrm{O}_{2}(y, z \geq 0.33)$ phases. The sol-gel synthesized sample (SG-LMNCO), on the other hand, has a single-phase structure with a homogeneous distribution of transition metal (TM) with respect to $\mathrm{Li}$ in the TM layer. Here, $\mathrm{Li}_{2} \mathrm{MnO}_{3}$ domains do not form as the LMNCO phase crystallizes from a metal-citrate matrix where the cations are uniformly distributed. It is envisaged that these results clarify the structural ambiguities of this promising electrode material and, in doing so, pave the way for further advancement of Liand Mn-rich layered oxides. This work also accentuates the need for extra caution and complementary techniques during the structural characterization of novel complex materials, where the local structural and configurational (dis)order can lead to multiple metastable states entirely dependent on the synthetic route.

\section{ASSOCIATED CONTENT}

\section{(s) Supporting Information}

The Supporting Information is available free of charge at https://pubs.acs.org/doi/10.1021/acsaem.0c03027.

ICP-OES results, Pawley refinements-XRD, Raman spectroscopy, quantification of X-ray energy-dispersive spectroscopy (XEDS) maps, magnetic measurements, structure analysis using FAULTS, Rietveld refinement using neutron diffraction data, in situ studies, electrochemistry (PDF)

\section{AUTHOR INFORMATION}

\section{Corresponding Author}

William R. Brant - Department of Chemistry-Ångström Laboratory, Uppsala University, SE-75121 Uppsala,

Sweden; (1) orcid.org/0000-0002-8658-8938;

Email: william.brant@kemi.uu.se

\section{Authors}

Ashok S. Menon - Department of Chemistry-Ångström Laboratory, Uppsala University, SE-75121 Uppsala, Sweden; (1) orcid.org/0000-0001-8148-8615

Seda Ulusoy - Department of Materials Science and Engineering, Uppsala University, SE-75103 Uppsala, Sweden

Dickson O. Ojwang - Department of Chemistry-Ångström Laboratory, Uppsala University, SE-75121 Uppsala, Sweden; (1) orcid.org/0000-0001-9304-8975

Lars Riekehr - Department of Chemistry-Ångström Laboratory, Uppsala University, SE-75121 Uppsala, Sweden
Christophe Didier - Australian Centre for Neutron Scattering, Australian Nuclear Science and Technology Organization, New South Wales 2232, Australia; School of Chemistry, University of New South Wales, Sydney 2052, Australia

Vanessa K. Peterson - Australian Centre for Neutron Scattering, Australian Nuclear Science and Technology Organization, New South Wales 2232, Australia; Institute for Superconducting \& Electronic Materials, Faculty of Engineering, University of Wollongong, Wollongong 2522,

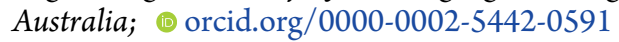

Germán Salazar-Alvarez - Department of Materials Science and Engineering, Uppsala University, SE-75103 Uppsala, Sweden; 이이. orcid.org/0000-0002-0671-435X

Peter Svedlindh - Department of Materials Science and Engineering, Uppsala University, SE-75103 Uppsala, Sweden

Kristina Edström - Department of Chemistry-Ångström Laboratory, Uppsala University, SE-75121 Uppsala, Sweden; (1) orcid.org/0000-0003-4440-2952

Cesar Pay Gomez - Department of Chemistry-Ångström Laboratory, Uppsala University, SE-75121 Uppsala, Sweden

Complete contact information is available at:

https://pubs.acs.org/10.1021/acsaem.0c03027

\section{Funding}

This research was funded by the Swedish Foundation for Strategic Research (SSF) within the Swedish national graduate school in neutron scattering (SwedNess). The authors also gratefully acknowledge funding from the Strategic Research Area StandUp for Energy and the Swedish Energy Agency. The Swedish research council, VR, is also acknowledged (Grants 349-2014-3946 and 2016-06959).

\section{Notes}

The authors declare no competing financial interest.

\section{ACKNOWLEDGMENTS}

The authors are grateful to Dr. Anita D'Angelo (Beamline scientist) at the Powder Diffraction beamline, Australian Synchrotron, as well as Dr. Chiu Tang (principal beamline scientist) and Dr. Stephen Thompson (senior beamline scientist) at the I11 High Resolution Powder Diffraction beamline at the Diamond Light Source (UK) for their help and guidance. The powder diffraction beamlines and sample environment team at ANSTO, Sydney are also acknowledged. A.S.M. is particularly grateful to colleagues Victor Pacheco, Dr. Adriano Francesco Pavan, and Dr. Ronnie Mogensen for their support and help.

\section{REFERENCES}

(1) Hu, S.; Pillai, A. S.; Liang, G.; Pang, W. K.; Wang, H.; Li, Q.; Guo, Z. Li-Rich Layered Oxides and Their Practical Challenges: Recent Progress and Perspectives. Electrochem. Energy Rev. 2019, 2, 277-311.

(2) Assat, G.; Foix, D.; Delacourt, C.; Iadecola, A.; Dedryvère, R.; Tarascon, J.-M. Fundamental interplay between anionic/cationic redox governing the kinetics and thermodynamics of lithium-rich cathodes. Nat. Commun. 2017, 8 (1), 2219.

(3) Kleiner, K.; Strehle, B.; Baker, A. R.; Day, S. J.; Tang, C. C.; Buchberger, I.; Chesneau, F.-F.; Gasteiger, H. A.; Piana, M. Origin of High Capacity and Poor Cycling Stability of Li-Rich Layered Oxides: A Long-Duration in Situ Synchrotron Powder Diffraction Study. Chem. Mater. 2018, 30 (11), 3656-3667. 
(4) Eum, D.; Kim, B.; Kim, S. J.; Park, H.; Wu, J.; Cho, S.-P.; Yoon, G.; Lee, M. H.; Jung, S.-K.; Yang, W.; Seong, W. M.; Ku, K.; Tamwattana, O.; Park, S. K.; Hwang, I.; Kang, K. Voltage decay and redox asymmetry mitigation by reversible cation migration in lithiumrich layered oxide electrodes. Nat. Mater. 2020, 19 (4), 419-427.

(5) Cui, C.; Fan, X.; Zhou, X.; Chen, J.; Wang, Q.; Ma, L.; Yang, C.; $\mathrm{Hu}$, E.; Yang, X.-Q.; Wang, C. Structure and Interface Design Enable Stable Li-Rich Cathode. J. Am. Chem. Soc. 2020, 142 (19), 89188927.

(6) Zhang, P.; Zhai, X.; Huang, H.; Zhou, J.; Li, X.; He, Y.; Guo, Z. Suppression of structural phase transformation of Li-rich Mn-based layered cathode materials with $\mathrm{Na}$ ion substitution strategy. Electrochim. Acta 2020, 349, 136402.

(7) Shukla, A. K.; Ramasse, Q. M.; Ophus, C.; Duncan, H.; Hage, F.; Chen, G. Unravelling structural ambiguities in lithium- and manganese-rich transition metal oxides. Nat. Commun. 2015, 6, 8711.

(8) Koga, H.; Croguennec, L.; Mannessiez, P.; Ménétrier, M.; Weill, F.; Bourgeois, L.; Duttine, M.; Suard, E.; Delmas, C. $\mathrm{Li}_{1.2} \mathrm{Mn}_{0.54} \mathrm{Ni}_{0.13} \mathrm{Co}_{0.13} \mathrm{O}_{2}$ with Different Particle Sizes as Attractive Positive Electrode Materials for Lithium-Ion Batteries: Insights into Their Structure. J. Phys. Chem. C 2012, 116 (25), 13497-13506.

(9) Boulineau, A.; Croguennec, L.; Delmas, C.; Weill, F. Reinvestigation of $\mathrm{Li}_{2} \mathrm{MnO}_{3}$ Structure: Electron Diffraction and High Resolution TEM. Chem. Mater. 2009, 21 (18), 4216-4222.

(10) Yin, S. C.; Rho, Y. H.; Swainson, I.; Nazar, L. F. X-ray/Neutron Diffraction and Electrochemical Studies of Lithium De/ReIntercalation in $\mathrm{Li}_{1-\mathrm{x}} \mathrm{Co}_{1 / 3} \mathrm{Ni}_{1 / 3} \mathrm{Mn}_{1 / 3} \mathrm{O}_{2}(\mathrm{x}=0-1)$. Chem. Mater. 2006, 18 (7), 1901-1910.

(11) Yu, H.; Ishikawa, R.; So, Y.-G.; Shibata, N.; Kudo, T.; Zhou, H.; Ikuhara, Y. Direct Atomic-Resolution Observation of Two Phases in the $\mathrm{Li}_{1.2} \mathrm{Mn}_{0.567} \mathrm{Ni}_{0.166} \mathrm{Co}_{0.067} \mathrm{O}_{2}$ Cathode Material for Lithium-Ion Batteries. Angew. Chem., Int. Ed. 2013, 52 (23), 5969-5973.

(12) Thackeray, M. M.; Kang, S.-H.; Johnson, C. S.; Vaughey, J. T.; Benedek, R.; Hackney, S. A. $\mathrm{Li}_{2} \mathrm{MnO}_{3}$-stabilized $\mathrm{LiMO}_{2}(\mathrm{M}=\mathrm{Mn}, \mathrm{Ni}$, Co) electrodes for lithium-ion batteries. J. Mater. Chem. 2007, 17 (30), 3112-3125.

(13) Mohanty, D.; Huq, A.; Payzant, E. A.; Sefat, A. S.; Li, J.; Abraham, D. P.; Wood, D. L.; Daniel, C. Neutron Diffraction and Magnetic Susceptibility Studies on a High-Voltage $\mathrm{Li}_{1.2} \mathrm{Mn}_{0.55} \mathrm{Ni}_{0.15} \mathrm{Co}_{0.10} \mathrm{O}_{2}$ Lithium Ion Battery Cathode: Insight into the Crystal Structure. Chem. Mater. 2013, 25 (20), 4064-4070.

(14) Whitfield, P.; Davidson, I.; Stephens, P.; Cranswick, L.; Swainson, I. Diffraction analysis of the lithium battery. Z. Kristallogr. 2007, 2007, 483-488.

(15) Warren, B. E. X-Ray Diffraction in Random Layer Lattices. Phys. Rev. 1941, 59 (9), 693-698.

(16) Menon, A. S.; Ojwang, D. O.; Willhammar, T.; Peterson, V. K.; Edström, K.; Gomez, C. P.; Brant, W. R. Influence of Synthesis Routes on the Crystallography, Morphology, and Electrochemistry of $\mathrm{Li}_{2} \mathrm{MnO}_{3}$. ACS Appl. Mater. Interfaces 2020, 12 (5), 5939-5950.

(17) Leifer, N.; Penki, T. R.; Nanda, R.; Grinblat, J.; Luski, S.; Aurbach, D.; Goobes, G. Linking Structure to Performance of $\mathrm{Li}_{1.2} \mathrm{Mn}_{0.54} \mathrm{Ni}_{0.13} \mathrm{Co}_{0.13} \mathrm{O}_{2}$ ( $\mathrm{Li}$ and Mn rich NMC) Cathode Materials Synthesized by Different Methods. Phys. Chem. Chem. Phys. 2020, 22 (16), 9098-9109.

(18) Xiang, Y.; Yin, Z.; Zhang, Y.; Li, X. Effects of synthesis conditions on the structural and electrochemical properties of the $\mathrm{Li}$ rich material $\mathrm{Li}\left[\mathrm{Li}_{0.2} \mathrm{Ni}_{0.17} \mathrm{Co}_{0.16} \mathrm{Mn}_{0.47}\right] \mathrm{O}_{2}$ via the solid-state method. Electrochim. Acta 2013, 91, 214-218.

(19) Riekehr, L.; Liu, J.; Schwarz, B.; Sigel, F.; Kerkamm, I.; Xia, Y.; Ehrenberg, H. Effect of pristine nanostructure on first cycle electrochemical characteristics of lithium-rich lithium-nickel-cobaltmanganese-oxide cathode ceramics for lithium ion batteries. J. Power Sources 2016, 306, 135-147.

(20) Rao, C. N. R. Chemical synthesis of solid inorganic materials. Mater. Sci. Eng., B 1993, 18 (1), 1-21.

(21) Pechini, M. P. Method of preparing lead and alkaline earth titanates and niobates and coating method using the same to form a capacitor. U.S. Patent 3,330,697, issued July 11, 1967.
(22) Wallwork, K. S.; Kennedy, B. J.; Wang, D. The High Resolution Powder Diffraction Beamline for the Australian Synchrotron. AIP Conf. Proc. 2006, 879 (1), 879-882.

(23) Avdeev, M.; Hester, J. R. ECHIDNA: a decade of highresolution neutron powder diffraction at OPAL. J. Appl. Crystallogr. 2018, 51 (6), 1597-1604.

(24) Thompson, S. P.; Parker, J. E.; Potter, J.; Hill, T. P.; Birt, A.; Cobb, T. M.; Yuan, F.; Tang, C. C. Beamline I11 at Diamond: A new instrument for high resolution powder diffraction. Rev. Sci. Instrum. 2009, 80 (7), 075107.

(25) Studer, A. J.; Hagen, M. E.; Noakes, T. J. Wombat: The highintensity powder diffractometer at the OPAL reactor. Phys. B 2006, 385, 1013-1015.

(26) Pawley, G. Unit-cell refinement from powder diffraction scans. J. Appl. Crystallogr. 1981, 14 (6), 357-361.

(27) Coelho, A. TOPAS and TOPAS-Academic: an optimization program integrating computer algebra and crystallographic objects written in C++. J. Appl. Crystallogr. 2018, 51 (1), 210-218.

(28) Rietveld, H. M. Line profiles of neutron powder-diffraction peaks for structure refinement. Acta Crystallogr. 1967, 22 (1), 151152.

(29) Rietveld, H. A profile refinement method for nuclear and magnetic structures. J. Appl. Crystallogr. 1969, 2 (2), 65-71.

(30) Casas-Cabanas, M.; Reynaud, M.; Rikarte, J.; Horbach, P.; Rodriguez-Carvajal, J. FAULTS: a program for refinement of structures with extended defects. J. Appl. Crystallogr. 2016, 49 (6), 2259-2269.

(31) Serrano-Sevillano, J.; Reynaud, M.; Saracibar, A.; Altantzis, T.; Bals, S.; Van Tendeloo, G.; Casas-Cabanas, M. Enhanced electrochemical performance of Li-rich cathode materials through microstructural control. Phys. Chem. Chem. Phys. 2018, 20 (35), 2311223122.

(32) Momma, K.; Izumi, F. VESTA: a three-dimensional visualization system for electronic and structural analysis. J. Appl. Crystallogr. 2008, 41 (3), 653-658.

(33) Virtanen, P.; Gommers, R.; Oliphant, T. E.; Haberland, M.; Reddy, T.; Cournapeau, D.; Burovski, E.; Peterson, P.; Weckesser, W.; Bright, J.; van der Walt, S. J.; Brett, M.; Wilson, J.; Millman, K. J.; Mayorov, N.; Nelson, A. R. J.; Jones, E.; Kern, R.; Larson, E.; Carey, C. J.; Polat, I.; Feng, Y.; Moore, E. W.; VanderPlas, J.; Laxalde, D.; Perktold, J.; Cimrman, R.; Henriksen, I.; Quintero, E. A.; Harris, C. R.; Archibald, A. M.; Ribeiro, A. H.; Pedregosa, F.; van Mulbregt, P.; Vijaykumar, A.; Bardelli, A. P.; Rothberg, A.; Hilboll, A.; Kloeckner, A.; Scopatz, A.; Lee, A.; Rokem, A.; Woods, C. N.; Fulton, C.; Masson, C.; Häggström, C.; Fitzgerald, C.; Nicholson, D. A.; Hagen, D. R.; Pasechnik, D. V.; Olivetti, E.; Martin, E.; Wieser, E.; Silva, F.; Lenders, F.; Wilhelm, F.; Young, G.; Price, G. A.; Ingold, G.-L.; Allen, G. E.; Lee, G. R.; Audren, H.; Probst, I.; Dietrich, J. P.; Silterra, J.; Webber, J. T.; Slavič, J.; Nothman, J.; Buchner, J.; Kulick, J.; Schönberger, J. L.; de Miranda Cardoso, J. V.; Reimer, J.; Harrington, J.; Rodríguez, J. L. C.; Nunez-Iglesias, J.; Kuczynski, J.; Tritz, K.; Thoma, M.; Newville, M.; Kümmerer, M.; Bolingbroke, M.; Tartre, M.; Pak, M.; Smith, N. J.; Nowaczyk, N.; Shebanov, N.; Pavlyk, O.; Brodtkorb, P. A.; Lee, P.; McGibbon, R. T.; Feldbauer, R.; Lewis, S.; Tygier, S.; Sievert, S.; Vigna, S.; Peterson, S.; More, S.; Pudlik, T.; Oshima, T.; Pingel, T. J.; Robitaille, T. P.; Spura, T.; Jones, T. R.; Cera, T.; Leslie, T.; Zito, T.; Krauss, T.; Upadhyay, U.; Halchenko, Y. O.; Vázquez-Baeza, Y.; SciPy, C. SciPy 1.0: fundamental algorithms for scientific computing in Python. Nat. Methods 2020, 17 (3), 261272.

(34) Xiao, J.; Chernova, N. A.; Whittingham, M. S. Layered Mixed Transition Metal Oxide Cathodes with Reduced Cobalt Content for Lithium Ion Batteries. Chem. Mater. 2008, 20 (24), 7454-7464.

(35) Greedan, J. E. Geometrically frustrated magnetic materials. J. Mater. Chem. 2001, 11 (1), 37-53.

(36) Chernova, N. A.; Ma, M.; Xiao, J.; Whittingham, M. S.; Breger, J.; Grey, C. P. Layered $\mathrm{Li}_{\mathrm{x}} \mathrm{Ni}_{\mathrm{y}} \mathrm{Mn}_{\mathrm{y}} \mathrm{Co}_{1-2 \mathrm{y}} \mathrm{O}_{2}$ Cathodes for Lithium Ion Batteries: Understanding Local Structure via Magnetic Properties. Chem. Mater. 2007, 19 (19), 4682-4693. 
(37) Julien, C. M.; Ait-Salah, A.; Mauger, A.; Gendron, F. Magnetic properties of lithium intercalation compounds. Ionics 2006, 12 (1), $21-32$.

(38) Fertman, E.; Dolya, S.; Desnenko, V.; Beznosov, A.; Kajňaková, M.; Feher, A. Cluster glass magnetism in the phase-separated $\mathrm{Nd}_{2 / 3} \mathrm{Ca}_{1 / 3} \mathrm{MnO}_{3}$ perovskite. J. Magn. Magn. Mater. 2012, 324 (19), 3213-3217.

(39) Goodenough, J. B. Direct Cation-Cation Interactions in Several Oxides. Phys. Rev. 1960, 117 (6), 1442-1451.

(40) Terayama, K.; Ikeda, M. Study on thermal decomposition of $\mathrm{MnO}_{2}$ and $\mathrm{Mn}_{2} \mathrm{O}_{3}$ by thermal analysis. Trans. Jpn. Inst. Met. 1983, 24 (11), 754-758.

(41) Kim, J.-W.; Lee, H.-G. Thermal and carbothermic decomposition of $\mathrm{Na}_{2} \mathrm{CO}_{3}$ and $\mathrm{Li}_{2} \mathrm{CO}_{3}$. Metall. Mater. Trans. B 2001, 32 (1), $17-24$.

(42) Chen, M.; Hallstedt, B.; Gauckler, L. J. Thermodynamic assessment of the Co-O system. J. Phase Equilib. 2003, 24 (3), 212227.

(43) Lee, J.; Dupre, N.; Jeong, M.; Kang, S.; Avdeev, M.; Gong, Y.; Gu, L.; Yoon, W. S.; Kang, B. Fully Exploited Oxygen Redox Reaction by the Inter-Diffused Cations in Co-Free Li-Rich Materials for High Performance Li-Ion Batteries. Advanced Science 2020, 7 (17), 2001658.

(44) Lun, Z.; Ouyang, B.; Kwon, D.-H.; Ha, Y.; Foley, E. E.; Huang, T.-Y.; Cai, Z.; Kim, H.; Balasubramanian, M.; Sun, Y.; Huang, J.; Tian, Y.; Kim, H.; McCloskey, B. D.; Yang, W.; Clément, R. J.; Ji, H.; Ceder, G. Cation-disordered rocksalt-type high-entropy cathodes for Li-ion batteries. Nat. Mater. 2021, 20, 214-221.

(45) Yu, H.; So, Y.-G.; Ren, Y.; Wu, T.; Guo, G.; Xiao, R.; Lu, J.; Li, H.; Yang, Y.; Zhou, H.; Wang, R.; Amine, K.; Ikuhara, Y. Temperature-Sensitive Structure Evolution of Lithium-ManganeseRich Layered Oxides for Lithium-Ion Batteries. J. Am. Chem. Soc. 2018, 140 (45), 15279-15289.

(46) Chen, C.-J.; Pang, W. K.; Mori, T.; Peterson, V. K.; Sharma, N.; Lee, P.-H.; Wu, S.-h.; Wang, C.-C.; Song, Y.-F.; Liu, R.-S. The Origin of Capacity Fade in the $\mathrm{Li}_{2} \mathrm{MnO}_{3} \cdot \mathrm{LiMO}_{2}(\mathrm{M}=\mathrm{Li}, \mathrm{Ni}, \mathrm{Co}, \mathrm{Mn})$ Microsphere Positive Electrode: An Operando Neutron Diffraction and Transmission X-ray Microscopy Study. J. Am. Chem. Soc. 2016, 138 (28), 8824-8833. 